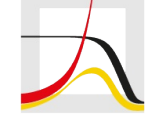

MAX PLANCK INSTITUTE

FOR DEMOGRAPHIC RESEARCH

Konrad-Zuse-Strasse 1 · D-18057 Rostock · Germany · Tel +49 (0) 3812081 - 0 - Fax +49 (0) 3812081 - $202 \cdot$ www.demogr.mpg.de

MPIDR Working Paper WP 2021-013 I June 2021

https://doi.org/10.4054/MPIDR-WP-2021-013

Mental health before and during the

COVID-19 pandemic:

The role of partnership and parenthood

status in growing disparities between

types of families.

Nicole Hiekel

Mine Kühn I kuehn@demogr.mpg.de 
Nicole Hiekel ${ }^{1}$ and Mine Kühn ${ }^{2}$

\title{
Mental health before and during the COVID-19 pandemic: The role of partnership and parenthood status in growing disparities between types of families.
}

\begin{abstract}
This study set out to investigate mental health inequalities by family type and gender during the COVID-19 pandemic in Germany. We analyzed three dimensions of mental health (i.e., selfreported stress, exhaustion, and loneliness) one year before the pandemic and in spring 2020. First, two-parent families emerge as a vulnerable group, as they experienced the largest increases in levels of stress and exhaustion, converging with those experienced by single parents. Second, a gender gap emerges during this global health crisis, with women, and particularly mothers, carrying the heaviest burdens, and having the greatest mental health declines. The findings presented here underline the empirical and substantive value of studying mental health inequality from a multidimensional perspective and over time. Based on these findings, we urge policy-makers to consider more seriously the disproportionate burdens that members of families, and women in particular, have been carrying due to the pandemic, both directly and indirectly.
\end{abstract}

\section{KEYWORDS}

Mental health inequalities, Covid-19 pandemic, gender inequality, family types, stress, exhaustion, loneliness

\footnotetext{
${ }^{1}$ Institute of Sociology and Social Psychology, University of Cologne, Germany

${ }^{2}$ Max Planck Institute for Demographic Research, Rostock, Germany
} 


\section{INTRODUCTION}

There is increasing evidence that the COVID-19 pandemic is exacerbating a wide range of preexisting social and economic inequalities. This may also be the case for mental health disparities. A growing body of COVID-19 research has demonstrated that the pandemic is having adverse effects on people's mental health through rapid increases in stress and anxiety triggered by the health threat the virus implies; the impact of the lack of social integration and support; the difficulties people face in accessing support services; and the impact of the economic downturn (Adams-Prassl et al. 2020; Gabor et al. 2020; Gassman-Pines et al. 2020; Hart and Han 2020; Westrupp et al. 2020). It is, however, currently unknown whether the public health measures that were implemented by many countries affected by the COVID-19 pandemic with the goal of slowing down the transmission rate of the coronavirus affected certain social groups more negatively than others. Given the consistent evidence that before the pandemic, mental health had been unequally distributed across the population based on partnership and parenthood status, the efforts to "flatten the curve" may have further contributed to growing disparities in the mental health levels of different types of families. If so, this exacerbation of mental health inequalities may be considered one of the unintended negative consequences of public health interventions in societies lacking herd immunity.

Like in many other countries affected by the COVID-19 pandemic, in Germany, the government shut down large parts of public life in spring 2020. The legally enforced restrictions on physical contact; the closure of shops, restaurants, and service facilities not considered essential; and the mandate to wear mouth-nose protection when using public facilities and public transport affected the behavior of large parts of the population to similar degrees. However, some of these measures affected the working-age population and parents more than other groups. In particular, the 
nationwide closure of schools and day care centers led to additional child care responsibilities for the parents of minor children. In addition, for the first time ever, large parts of the working population were instructed to work from home, with only essential workers being permitted to leave their homes for work (with the implied higher potential exposure to the virus) and having access to formal care for their children. Legally binding contact restrictions in public spaces and orders to "stay home" meant that access to (physical) social integration and support between members of different households was greatly reduced, which affected unpartnered individuals and single parents in particular.

In this paper, we investigate how family status - differentiated by partnership status and parenting status - is associated with individual mental health before and during the COVID-19 pandemic, and how these associations differed for men and women.

For our analysis, we use data from the Panel Analysis of Intimate Relationships and Family Dynamics (Pairfam). Between May and July, a COVID-19 special survey was conducted that collected information on the consequences of the COVID-19 pandemic on individuals' private lives and personal relationships. Due to the richness of the measurements on well-being of the survey data from this large German panel and the relatively large sample size, we are able to compare individual mental health disparities by family status before and during the pandemic. We compare subpopulations by gender and by the four most prevalent family types of individuals in the 18-45 age group.

We contribute to the literature on the COVID-19 pandemic in three key ways. First, our study is the first to focus on individuals with different family statuses. Existing studies have focused on single subgroups, such as adolescents and parents (Gabor et al. 2020; Janssen et al. 2020; Zoch et al. 2020). By contrast, we consider singles, childless couples, partnered parents, as well as single 
parents. This approach enables us to systematically identify similarities and differences between men's and women's health that can be attributed to their partnership status, their parenthood status, or both. Second, using an existing nationally representative panel and high-quality longitudinal data allows us to consider individual mental health prior to the pandemic, and compare it with the mental health status of the same individuals during the pandemic. Thus, our study has large methodological advantages over studies using convenience samples, which limits the wider applicability of their findings. Third, we provide empirical evidence of the emergence of new inequalities in mental health between men and women in particular types of families that may be rooted in their experiences during the pandemic. Beyond adding to our understanding of how the current coronavirus pandemic has contributed to the growing disparities in mental health between different social groups, we believe that studying in a quasi-natural experiment how the external shocks of the pandemic and the policy responses to it have shaped the social context in which individuals respond can provide us with a better understanding of the mechanisms linking the complex relationships between partnership status, parenthood, and mental health.

\section{BACKGROUND}

\section{PRE-PANDEMIC INEQUALITIES IN MENTAL HEALTH BY FAMILY STATUS}

\section{Partnership status and mental health}

Family scholars have long studied the relationship between family status and mental health. Empirical research that has predominantly focused on comparisons between married and nonmarried people has consistently shown that married people have better health outcomes than their unmarried counterparts (Carr and Springer 2010). The beneficial effects of marriage were mainly explained by two mechanisms: selection and causation. The selection perspective emphasizes that healthier people are more likely to marry and remain married (positive health selection). The 
causation perspective offers two explanations for these effects: a) the resource perspective argues that marriage provides economic and psychological resources that enhance the psychological wellbeing of the partners, and that reduce their psychological distress; while b) the crisis perspective argues that married people are healthier than people who have experienced a union dissolution, as divorce is associated with stress, which is harmful to mental health (Amato 2000). The recent availability of longitudinal data on married and unmarried people has enabled scholars to investigate the underlying mechanisms of the marriage effect, and most have found evidence for both the selection and the causation perspectives (Goldman 2001).

Despite the increasing relevance of unmarried cohabitation in the demographic landscape, cohabiting individuals have not yet received much attention in research on inequalities in mental well-being by family status. The few studies that have compared the mental health of people in different union types have found for the US context that differences in relationship quality and union stability between married and unmarried couples account for the observation that cohabitation seems to offer fewer mental health benefits than marriage (Brown 2000; Marcussen 2005). However, differences in the mental health of married and cohabiting individuals have not been found to be significant in countries where cohabitation is more normative (Stavrova and Fetchenhauer 2015). Given that most of the Germans of the cohorts studied here cohabited before eventually getting married (Hiekel 2014), it is likely that Germans who cohabit benefit from marriage-like resources.

Furthermore, there is a large body of literature showing that union dissolution and widowhood are associated with adverse changes in mental health. Studies that have investigated the relationship between having poor mental health and experiencing divorce, separation, or widowhood have shown that this association can be partly explained by selection; i.e., that individuals with poor 
health are more prone to experience these life events. Most longitudinal studies that have examined this relationship have reported that the short-term effects of divorce (Blekesaune 2008; Meadows et al. 2008; Metsä-Simola and Martikainen 2013; Metsä-Simola and Martikainen 2014; Strohschein et al. 2005) and of widowhood (Moon et al. 2013) on mental health are stronger than the long-term effects. However, there is also evidence of persistent long-term effects (Johnson and Wu 2002; Metsä-Simola and Martikainen 2013; Waite et al. 2009).

To explain the adverse effects of divorce or widowhood on mental health, the stress model is often proposed. Amato (2000) distinguished between partnership loss as a stressful event from which individuals tend to recover, and partnership loss as a process that initiates an accumulation of life strains that negatively affect individuals' mental health in the long run, such as economic hardship, social isolation, and single parenthood.

\section{Parental status and mental health}

There is a large and diverse body of research investigating parents' psychological and emotional well-being. Some studies have suggested that parents report higher levels of well-being (e.g., greater life satisfaction or happiness) than adults without children, while other studies have shown that parents have lower levels of well-being (e.g., lower life satisfaction, more depression, anxiety, and stress) than non-parents (see Nelson et al. 2014; Umberson et al. 2010 for reviews). Recent work has explained these mixed findings using the framework of the demands-rewards perspective, which argues that parenthood brings both demands (i.e., physical, mental, and financial efforts) and rewards (i.e., achievement of parenting goals) to the lives of adults (Nomaguchi and Milkie 2020), and thus concludes that parenting elicits a "mixed bag" of emotions (Musick et al. 2016). Negraia and Augustine (2020) unpacked this mixed bag and found that compared to non-parents, the parents of young children experience both more negative emotions (i.e., stress and fatigue) and 
more positive emotions (i.e., more happiness and less sadness). However, whether the costs and rewards of parenthood are balanced seems to depend on the parents' social status and parental stage (Nelson et al. 2014; Ruppanner et al. 2019; Simon and Caputo 2019), as well as on the social policy context (Glass et al. 2016). There is consistent evidence that the parents of younger children experience higher levels of psychological distress than the parents of older children and the childless (Evenson and Simon 2005). Such findings are often explained by the extreme time constraints, the reduced relationship quality between the parents, the demands of child care, and the increased financial responsibilities that the parents of young children often experience (Negraia and Augustine 2020). These effects tend to be greater among socioeconomically disadvantaged social groups, who have fewer resources to cope with these demands (Nomaguchi and Milkie 2020). Furthermore, a cross-national comparison uncovered a gap in mental health between parents depending on their social policy context, with the parental disadvantage being smallest in countries that provide high levels of family support. Thus, the results of this comparison suggest that the levels of support a nation provides to parents to help them raise their children can have positive effects on the parents' mental health (Glass et al. 2016).

Single parents tend to experience greater parenting stress, which can negatively affect their mental health, and these effects may, in turn, intersect with the effects of gender and socioeconomic status. Given that they often have to provide the entire household income, single parents, and particularly single mothers, face higher levels of stress due economic pressures, caregiving responsibilities, and work-family conflicts. There is evidence that compared to partnered mothers, single mothers report less happiness and more sadness, stress, and fatigue associated with parenting (Kühn 2018; Meier et al. 2016). 
Although the family policies in Germany are more generous than those in the US, where most of these studies were performed, based on these theoretical and empirical considerations, we expect to find that when we compare the initial (i.e., the pre-pandemic) mental health of various groups, partnered individuals had better mental health than unpartnered individuals; couples without children had better mental health than couples with children; and partnered parents had better mental health than single parents (Hypothesis 1).

\section{INEQUALITIES IN MENTAL HEALTH BY FAMILY STATUS DURING THE PANDEMIC}

During the COVID-19 pandemic, individuals with a partner in the household could compensate for the lack of social contacts outside the home to some extent. However, the sudden social isolation associated with the pandemic may have negatively affected the mental well-being of unpartnered individuals in particular. For some of these individuals, the lockdown may have interrupted a coping strategy of cultivating a wide social support network of friends and acquaintances to compensate for the absence of a partner. Moreover, the lockdown may have prevented these individuals from maintaining social contacts outside of their own household that helped them in pursuing their goal of finding a partner. For single individuals without children in the household, the lack of social life may have led to their leisure time becoming a source of boredom, loneliness, and worry.

Due to the legally binding restrictions on contact in public spaces and orders to "stay home" during the lockdown, people's access to (physical) social interactions and support from members of different households was greatly reduced. The regular access people had to face-to-face social interactions with other adults not living in the same household, which was once taken for granted, vanished from one day to the next. Colleagues were working from home, or were required to adhere to strict physical distancing practices while at the workplace. Associations and clubs that previously 
brought people together to play sports, listen to music, maintain traditions, or cultivate other hobbies canceled their activities. Friends and family members were strongly advised to adhere to physical distancing due to a lack of knowledge about how the virus was transmitted.

For many parents with dependent children, the closure of day care centers and schools made it much more difficult for them to juggle their many responsibilities, including participating in the labor market and caring for their children. Employed single parents and parents in dual-earner households were most affected by these closures. Many of these parents were forced to either to cut their working hours, or, when possible (especially if they were in a high-skilled job), to combine working from home while looking after their children (Andrew et al. 2020; Huebener et al. 2021). Previous studies have shown that child care instability is stressful for parents, and especially for single mothers, who tend to have difficulties coping with care disruptions (Pilarz and Hill 2017). Thus, it is likely that the pandemic led to new levels of role strain, a term used to describe "the felt difficulty in fulfilling role obligations." Role strain tends to occur when parents experience pressure to engage in contradictory activities, and thus experience conflicts of time, place, or resource allocation (Goode 1960: p.483). Family relationships are the most immediate and persistent context in which role strain may negatively affect individual well-being, because formal withdrawal from social obligations is difficult, and informal withdrawal may lead to both feelings of distress and the imposition of guilt and sanctions by family members.

Based on these theoretical considerations, we expect to observe that differences in mental health by family status became more pronounced during the lockdown between unpartnered and partnered individuals, between couples with and couples without children, and between single-parent and two-parent families (Hypothesis 2). 
GENDER DIFFERENCES IN THE LINK BETWEEN FAMILY STATUS AND MENTAL HEALTH

Gender differences in the association between family status and mental health are often attributed to mothers having more role obligations within the family, which decreases the beneficial effects of partnership and parenthood on women's mental health. The type of roles that women tend to adopt within the family include providing unpaid care work, and performing emotional work and housework for the benefit of their partners and their children. As these tasks are considered timeconsuming and onerous, mothers may have a greater mental load and be more prone to frustration than fathers. Previous studies have clearly shown that the costs of parenthood are more severe for mothers than for fathers (Nomaguchi et al. 2005; Ruppanner et al. 2019), with fathers spending more time than mothers engaged in activities that bring joy and are associated with less stress, such as play and leisure activities (Musick et al. 2016). Furthermore, most single parents are women, and single mothers tend to have fewer resources and less support to buffer their parenting (and other sources of) stress than men (Burgard and Ailshire 2013; Negraia et al. 2018). While the beneficial effects of marriage and the negative effects of union dissolution on mental health seem to affect women and men similarly, the symptoms they experience tend to differ. While unmarried women report having more depressive symptoms than married women, unmarried men often increase their alcohol use (Simon 2002).

We expect to find that the initial (i.e., pre-pandemic) mental health of mothers was lower than that of fathers (Hypothesis 3). Furthermore, we investigate using an explorative approach the gender differences in partnership status and mental health.

The increase in the mental health disadvantages of women during the lockdown may be linked to the clear gender inequalities in paid work, housework, and care work, all of which were strongly 
affected by the measures the government imposed to tackle the COVID-19 pandemic. The existing evidence on the consequences of the COVID-19 lockdown suggests that while men increased their overall contributions to housework and care work from low initial levels, the lockdown was not the great equalizer, but rather reaffirmed or even magnified the existing gender inequalities within couples with children (Czymara et al. 2021; Hank and Steinbach 2020; Kreyenfeld and Zinn 2020; Möhring et al. 2020). Therefore, it is likely that after the onset of the pandemic, women's unpaid workload further increased from already high levels, as during the spring lockdown, families were spending more time at home than they were before the pandemic. Thus, during the lockdown, women were spending even more hours on child care, home schooling, meal preparation, cleaning, and grocery shopping. On a different note, there is initial evidence for Germany suggesting that the pandemic has had gender-specific labor market consequences, as more women than men have been engaged in stressful and risky work on the frontlines because of their overrepresentation in systemrelevant occupations (Adams-Prassl et al. 2020; Bünning et al. 2020; Zoch et al. 2020). We thus expect to find clear gender differences in mental health, with mothers having lower levels of mental health than fathers (Hypothesis 4). The differences in the mental health levels of unpartnered women and unpartnered men are investigated in an explorative fashion.

\section{DATA AND SAMPLE}

The Panel Analysis of Intimate Relationships and Family Dynamics (Pairfam) has been running since 2008/2009 (Brüderl et al. 2021; Huinink et al. 2011). Currently, there are 11 roughly annual regular panel waves representative of three German birth cohorts (1971-72, 1981-83, and 1991-93; as well as 2001-2003 since wave 11).

Between May 19 and July 13, 2020, an additional, optional 15-minute web-based survey covering the consequences of the COVID-19 pandemic on the respondents' private lives and personal 
relationships was conducted. $\mathrm{N}=3,183$ (of the eligible 9,640) respondents participated in the online survey. The majority of the data had been collected by mid-June. A majority of the survey participants were women (58\%). Other socio-demographic differences (i.e., cohort, family status) between the main sample and the coronavirus sample were relatively small.

We selected $n=1,919$ respondents who participated in both the pre-pandemic wave 11 - which was collected in November 2018-March 2019, and thus roughly one year before the COVID-19 virus was discovered and started spreading around the world - and the coronavirus survey conducted in spring 2020. The vast majority of these respondents had provided information on their partnership and parenthood status, and could thus be classified according to one of the four family types we address in this study. We excluded $n=16$ respondents with missing data on any of the mental health measures we used to derive our dependent variables. Our analytical sample comprised $n=1,865$ individuals, with women (60\%) and university graduates (57\%) being overrepresented. In the 2020 data collection, $46 \%$ of the respondents were in their late thirties, while $30 \%$ were in their late forties, and $20 \%$ were in their late twenties. At the time of the interview, $87 \%$ of the respondents reported that the government-mandated restrictions on social contact were still in place. In addition, $83 \%$ of the parents of school-aged children reported that their children's schools were still (partially) closed, and 74\% of the parents of preschool-aged children reported that their children's day care centers were (partially) closed.

\section{MEASUREMENTS}

Pairfam assesses mental health along different dimensions, mainly using established scales. These scales tend to be modified by shortening the original number of items through tapping into the construct, or by unifying the scale length. We decided to focus on those dimensions of well-being for which we could obtain measurements both before and during the pandemic. This resulted in 
three dimensions of mental well-being: levels of stress, lack of activity, and loneliness. All of these dimensions were measured by asking respondents "How have you been feeling, for the most part, during the past four weeks?" The categories ranged from one "does not at all apply" to five "applies absolutely."

The original stress scale was developed by Fliege et al. (2001)and was implemented by covering the feelings "stressed," "overburdened," and "under pressure." The activity scale, which was based on the psychological state scale developed by Abele-Brehm \& Brehm (1986), assessed whether the respondents were feeling "active" and "full of energy." We reversed the activity scales to unify all of the mental well-being indicators so that they pointed in the same direction. The indicators for loneliness, which stemmed from the UCLA loneliness scale developed by Russel et al. (1980), measured the extent to which the respondents were "feeling alone." In the COVID survey, a new additional item was introduced that was adapted from the Psychological Adjustment to the COVID19 pandemic study (Schmidt et al. 2021). This item measured the extent to which the respondents were "feeling lonely."

We obtained three scores for the mental health dimensions stress, lack of energy, and loneliness by summing answers to up to three questions for each dimension, with a higher score indicating worse mental well-being. Within each survey wave, we standardized each score to have a mean of zero and a standard deviation of one.

Based on the information that the respondents provided in both surveys about the people with whom they were co-residing, we can identify the partnership status and parenthood status of the respondents, and determine the four most common family types in Germany: namely, living single, living with a partner and without child(ren), living with a partner and child(ren), and living without a partner and with child(ren). We are aware that we are engaged a number of simplifications when 
we categorize individuals into different family types using these two indicators. First, we deliberately ignore non-resident partners. We feel that this approach is justified by the theoretical considerations we presented above, as particularly during the lockdown, which imposed restrictions on contacts, co-residence was a stronger than normal precondition for securing support and social integration. Second, we ignore non-resident children. Given the age range of our sample, most of these children were co-residing with an ex-partner. We believe that the main implications of the exclusion of these children are that we may underestimate the care burdens of the respondents in our sample, and particularly those of the respondents in the family types characterized by the absence of co-resident children. Finally, we deliberately ignore household members other than each respondent's partner and children. The small number of families in our sample that included other co-resident members, and the diversity of the types of relationships between the respondents and these additional household members, made it impossible for us to arrive at a subdivision that was more nuanced and still meaningful. As a robustness check, we re-analyzed all data excluding these cases. The findings presented here are not biased by their inclusion. Obviously, individuals may have switched from one family type to another between the first and the second survey. In our sample, $x \%$ of respondents belonged to a different family type in 2019 than they did in 2020.

\section{ANALYTICAL APPROACH}

We ran a set of OLS regression models with the standardized mental health score for each of the three indicators as the dependent variable. To test hypotheses 1 and 2 regarding whether the respondent's family type was (differently) associated with mental health before and during the pandemic, we included the family type as the key explanatory variable, and controlled for the respondent's gender, educational attainment, and birth cohort membership. In the model predicting mental health during the pandemic, we additionally included the respondent's corresponding pre- 
pandemic mental health score in order to account for floor and ceiling effects. To test hypotheses 3 and 4 regarding whether gender differences in the associations between the respondent's family type and mental health are reproduced or emerge before and during the pandemic, we additionally included an interaction term between each family type and gender in each of the models addressing one of the three mental health indicators.

\section{RESULTS}

DESCRIPTIVE FINDINGS ON MENTAL HEALTH BEFORE AND DURING THE PANDEMIC

How did respondents evaluate their mental health in spring 2020, and how did these reports differ roughly one year prior to the pandemic? We report the distributions of three mental health indicators at two times of measurement in Table 1. Our sample had relatively high levels of stress both before and during the pandemic. It may, however, be surprising that the stress level of the sample was lower in 2020 than in 2019, and that this pattern applied to all four family types studied here. Although it is not the aim of this paper to explain the reduction in the stress levels of the population studied here after the onset of pandemic, other studies have reported similar observations, and have suggested that this decline in overall stress levels is a positive side effect of social distancing, which for many people meant that they had fewer appointments, spent less time commuting from home to work, and had fewer potentially conflictual social contacts (Craig and Churchill 2021). We also find, however, that the respondents were clearly more likely to be experiencing a lack of energy and loneliness during the pandemic than one year previously. 
Table 1. Descriptive results for $\mathrm{n}=1,865$ men and women. Percentages if not indicated otherwise.

\begin{tabular}{|c|c|c|c|c|c|c|}
\hline \multirow[b]{2}{*}{$\begin{array}{l}\text { Individual } \\
\text { variables }\end{array}$} & \multicolumn{2}{|c|}{ Full Sample } & \multicolumn{2}{|c|}{ Women } & \multicolumn{2}{|c|}{ Men } \\
\hline & $\begin{array}{l}\text { Pre- } \\
\text { pandemic }\end{array}$ & $\begin{array}{l}\text { During } \\
\text { pandemic }\end{array}$ & $\begin{array}{l}\text { Pre- } \\
\text { pandemic }\end{array}$ & $\begin{array}{l}\text { During } \\
\text { pandemic }\end{array}$ & $\begin{array}{l}\text { Pre- } \\
\text { pandemic }\end{array}$ & $\begin{array}{l}\text { During } \\
\text { pandemic }\end{array}$ \\
\hline \multicolumn{7}{|l|}{ Family type } \\
\hline Single parent & 7.56 & 5.84 & 9.98 & 8.63 & 3.98 & 1.73 \\
\hline $\begin{array}{l}\text { Two-parent } \\
\text { family }\end{array}$ & 50.83 & 51.85 & 51.98 & 53.24 & 49.14 & 49.80 \\
\hline Single & 16.62 & 15.28 & 13.85 & 12.14 & 20.72 & 19.92 \\
\hline $\begin{array}{l}\text { Childless } \\
\text { couple }\end{array}$ & 24.99 & 27.02 & 24.19 & 25.99 & 26.16 & 28.55 \\
\hline \multicolumn{7}{|c|}{ Mental health indicator ${ }^{a}$} \\
\hline \multirow[t]{2}{*}{ Stress } & $\bar{X}=3.07$ & $\bar{X}=2.81$ & $\bar{X}=3.12$ & $\bar{X}=2.92$ & $\bar{X}=3.01$ & $\bar{X}=2.64$ \\
\hline & $S D=1.04$ & $S D=1.13$ & $\mathrm{SD}=1.05$ & $\mathrm{SD}=1.15$ & $\mathrm{SD}=1.03$ & $\mathrm{SD}=1.08$ \\
\hline \multirow[t]{2}{*}{ Lack of energy } & $\bar{X}=2.78$ & $\bar{X}=2.96$ & $\bar{X}=2.78$ & $\bar{X}=3.04$ & $\bar{X}=2.77$ & $\bar{X}=2.86$ \\
\hline & $S D=0.89$ & $S D=0.91$ & $\mathrm{SD}=0.90$ & $\mathrm{SD}=0.93$ & $\mathrm{SD}=0.87$ & $\mathrm{SD}=0.87$ \\
\hline \multirow[t]{2}{*}{ Loneliness } & $\bar{X}=1.88$ & $\bar{X}=2.01$ & $\bar{X}=1.92$ & $X=2.10$ & $\bar{X}=1.82$ & $\bar{X}=1.88$ \\
\hline & $S D=1.08$ & $S D=1.10$ & $\mathrm{SD}=1.10$ & $S D=1.11$ & $\mathrm{SD}=1.06$ & $\mathrm{SD}=1.05$ \\
\hline
\end{tabular}

\section{Education}

All levels of

secondary

school degree

Tertiary school

56.57

54.96

58.6

degree

\section{Birth Cohort}

\begin{tabular}{rrrr}
$1991-93$ & 24.24 & 25.27 & 22.71 \\
$1981-83$ & 46.33 & 46.31 & 46.35 \\
$1971-73$ & 29.44 & 28.42 & 30.94 \\
\hline $\mathbf{N}$ & 1,865 & 1,112 & 753 \\
\hline
\end{tabular}

${ }^{a}$ Based on multiple indicators tapping into the dimensions stress, lack of energy, and loneliness; in the regression models, these have been included as z-standardized sum scores.

Source: Pairfam 11 and Corona Survey 
MULTIVARIATE FINDINGS ON GROUP DIFFERENCES IN MENTAL HEALTH BEFORE AND DURING THE PANDEMIC

\section{Differences in mental health by family type}

Figure 1 plots the results of two OLS regression models predicting the level of stress by family type before and during the pandemic expressed as marginal effects. The results of the full regression model are provided in the appendix of this paper (Table Al). One year prior to the pandemic, the predicted levels of stress indicate that there was a divide between parents and nonparents regardless of partnership status, with parents reporting levels of stress higher than the sample mean (which is set to zero due to a z-standardization of the sum score), and non-parents reporting levels of stress below the sample mean. As the confidence intervals suggest, singles, individuals in two-parent families, and individuals in childless unions did not differ statistically significantly from each other. This finding does not confirm the expected group differences formulated in Hypothesis 1. However, single parents clearly had higher levels of stress than any other family type, as the predicted stress level of individuals with this family type were close to half a standard deviation above the sample mean. During the spring lockdown, the predicted level of stress of single-parent families and of two-parent families converged, and created a stress level gap between parents and non-parents that was not evident prior to the pandemic. Thus, two-parent families had significantly higher stress levels than childless couples and singles during the pandemic. This finding confirms the expectation formulated in Hypothesis 2 that mental health inequalities would increase during the pandemic. 


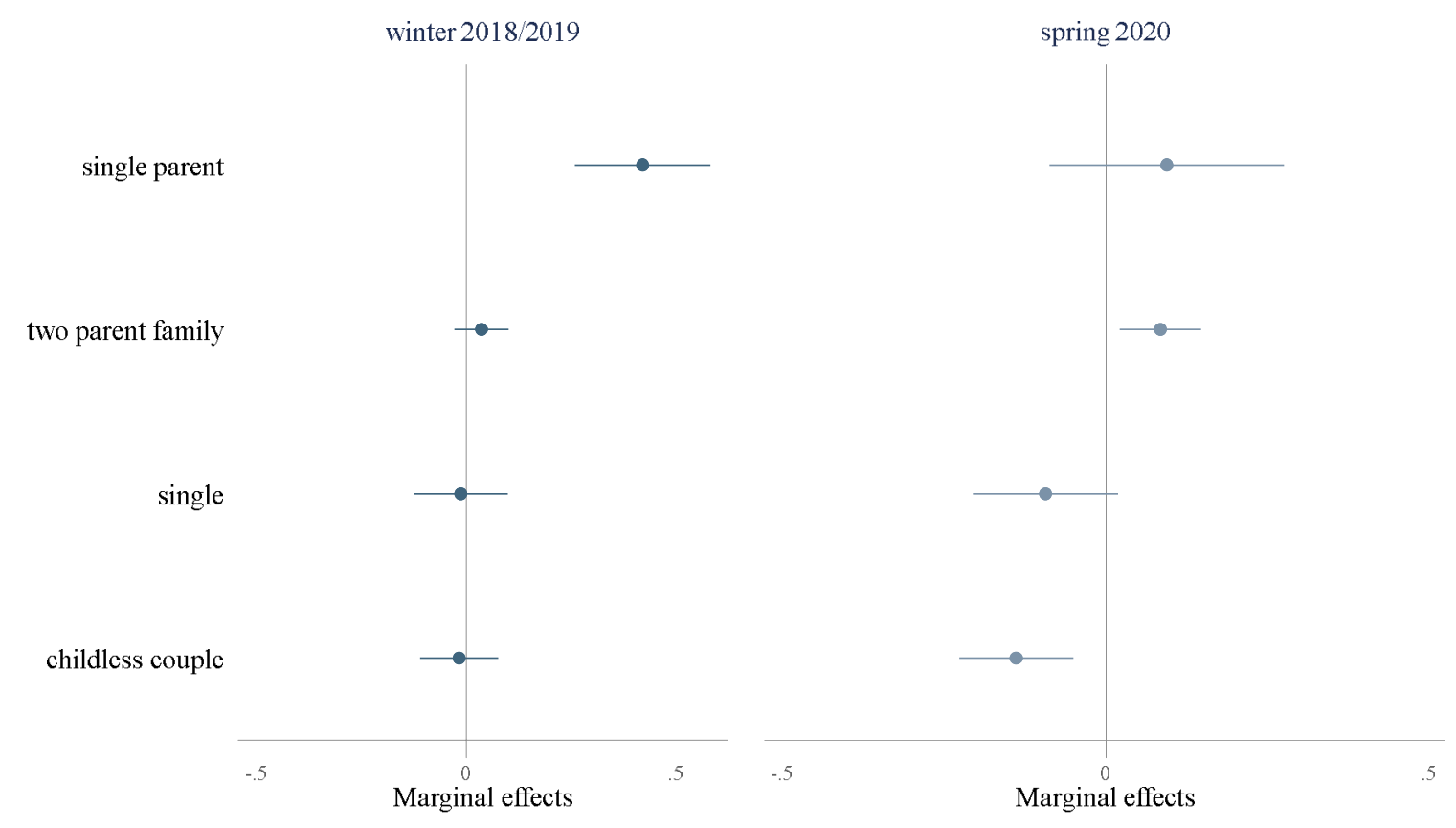

Note: Models control for sex, university degree (yes/no), cohort. 2020 model additionally controls for pre-pandemic level of stres: Source: Pairfam Wave 11 (2018/2019) Corona sample (2020).

Figure 1 Family type and stress before and during the pandemic in Germany.

In the same way as the results for stress levels were reported in Figure 1, Figure 2 plots the predicted levels of lacking energy by family type, expressed as marginal effects. One year prior to the pandemic, the predicted levels of lacking energy indicated that there was a divide between unpartnered and partnered individuals irrespective of their parenthood status, with the former reporting levels of lacking energy that were higher than the sample mean, and the latter reporting levels of lacking energy that were below the sample mean. However, the confidence intervals suggest that the none of the differences between the family types were statistically significant. Thus, Hypothesis 1 could not be confirmed. During the spring lockdown, we observe an emerging gap between the energy levels of single parents and other family types that barely failed to reach statistical significance, probably because the single parents comprised a relatively small share of the population (and our sample). The point estimates suggest that the combination of lacking a 
partner and having children during the pandemic meant that the single parents were particularly vulnerable to having higher levels of exhaustion as a dimension of low mental well-being. The differences between the other family types were not statistically different. Taken together, these results do not support the expectation formulated in Hypothesis 2 that group inequalities would increase at the intersection of parenthood and partnership status.

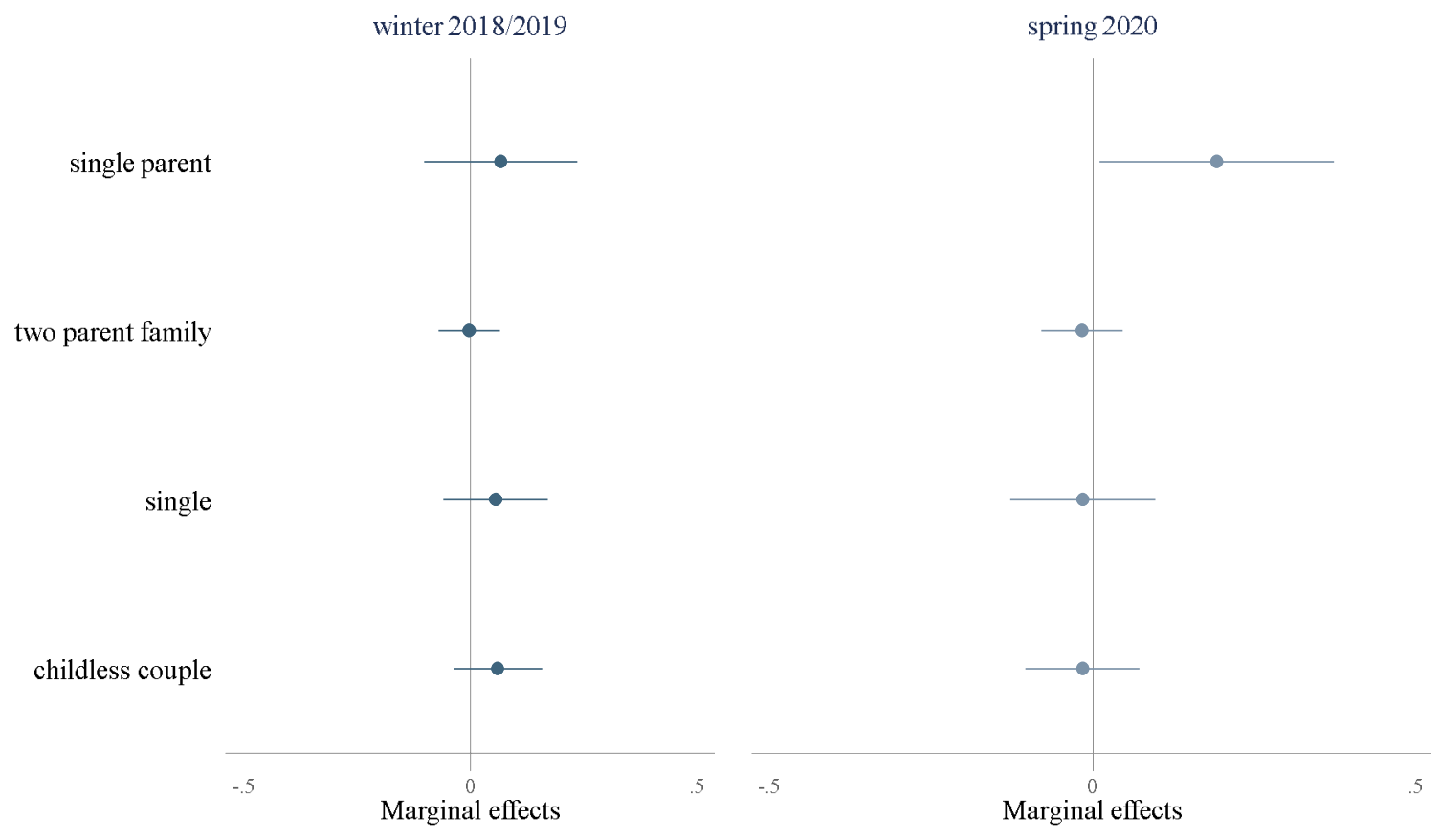

Note: Models control for sex, university degree (yes/no), cohort. 2020 model additionally controls for pre-pandemic level of energ: Source: Pairfam Wave 11 (2018/2019) Corona sample (2020).

Figure 2 Family type and lack of energy before and during the pandemic in Germany.

Associations between family type and levels of loneliness are shown in Figure 3. One year prior to the pandemic, levels of loneliness already clearly differed by family type, which suggests that partnership status, rather than parenthood status, was associated with feelings of loneliness. The predicted levels of loneliness among single parents and single individuals were situated more than half a standard deviation above the sample mean, with few significant differences between these two groups. Individuals in a two-parent family and individuals in a childless union reported similar 
levels of loneliness that were slightly below the sample mean. These findings do not reflect the mental health gradient that Hypothesis 1 suggested, but instead point toward a divide defined by partnership status. During the spring lockdown, the group differences became smaller, which contradicts the assumption made in Hypothesis 2 that the group disparities would grow. While the individuals in single family types reported lower levels of loneliness after than before the start of the pandemic, individuals who were living with a partner but no children reported higher levels of loneliness during the pandemic.

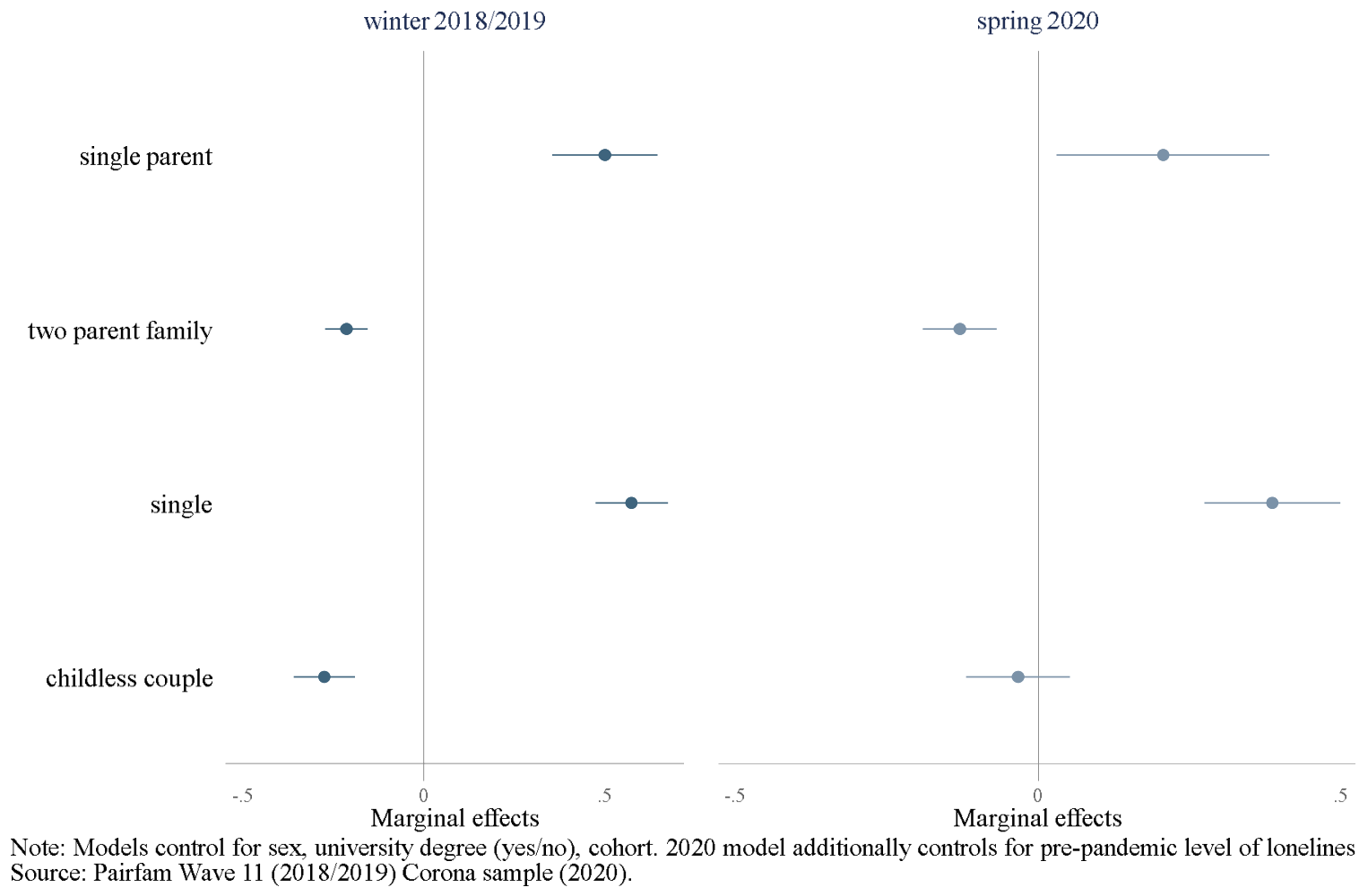

Figure 3 Family type and loneliness before and during the pandemic in Germany.

In the following, we offer some brief remarks about the associations between the control variables and the dimensions of mental health before and during the pandemic that are not displayed here (but see full models in the appendix, Table A1). University-educated respondents reported lower levels of stress and a lack of energy in the year before the pandemic. These systematic differences 
cannot be shown for loneliness at both time points, or with the data collected in spring 2020. Respondents of the oldest cohort sampled (born in the early 1970s) reported significantly lower levels of stress and lack of energy at both time points of measurement. Members of the youngest cohort (born in the early 1990s) reported lower levels of stress during the pandemic. With the exception of the reports on loneliness, the pre-pandemic reports on mental health did not differ systematically between women and men. However, the measures of stress, lack of energy, and loneliness during the lockdown revealed that women consistently reported having higher levels of stress, lack of energy, and loneliness than men.

\section{Gender differences in mental health by family type}

In the next section, we present the results of our analyses regarding the gender gap in mental health by family type before and during the pandemic. Based on the assumption that the gender inequalities in the labor market, in unpaid work, and in social integration are systematically and differently related to family status for men and women, we formulated the expectation that before the pandemic, the level of mental well-being would be lower for partnered mothers than for partnered fathers, for single mothers than for single fathers, for single men than for single women, and for childless partnered men than for childless partnered women (Hypothesis 3). Moreover, we formulated the expectation that in spring 2020, the restrictions on social contacts affected men and women differently, with mothers being more negatively affected than fathers (Hypothesis 4). Thus, in the next analytical step, we assessed whether men and women with the same family type differed in their mental well-being. To answer this question, we included an interaction term between each family type and sex of the respondents for each dimension of mental well-being studied here and two time points (i.e., pre-pandemic and during the spring lockdown). Figures 4, 5, and 6 plot the results of two OLS regression models, each of which predicts the level of stress (Figure 4), lack of 
energy (Figure 5), and loneliness (Figure 6) by family type and gender before (left panel) and during the pandemic (right panel) expressed as marginal effects (the full regression tables can be found in the appendix, Table A2).

Regarding stress levels one year prior to the pandemic, the results of an interaction model do not suggest that there were any gender differences by family type. The results for men and women largely mirror the findings presented in Figure 1. During spring 2020, there were no gender differences, with one exception: women in two-parent families reported significantly higher levels of stress than men in this family type. We also observe that for single-parent families, the point estimates of the predicted levels for men and women diverged, but did not reach statistical significance due to the low number of single fathers. The stress levels of single mothers converged at a lower level with the stress levels of women in two-parent families, whose stress levels increased. The main effect of gender in the interaction model was no longer statistically significant, which suggests that gender differences in the stress levels of men and women in spring 2020 could be explained by the increase in stress among women who were mothers. 


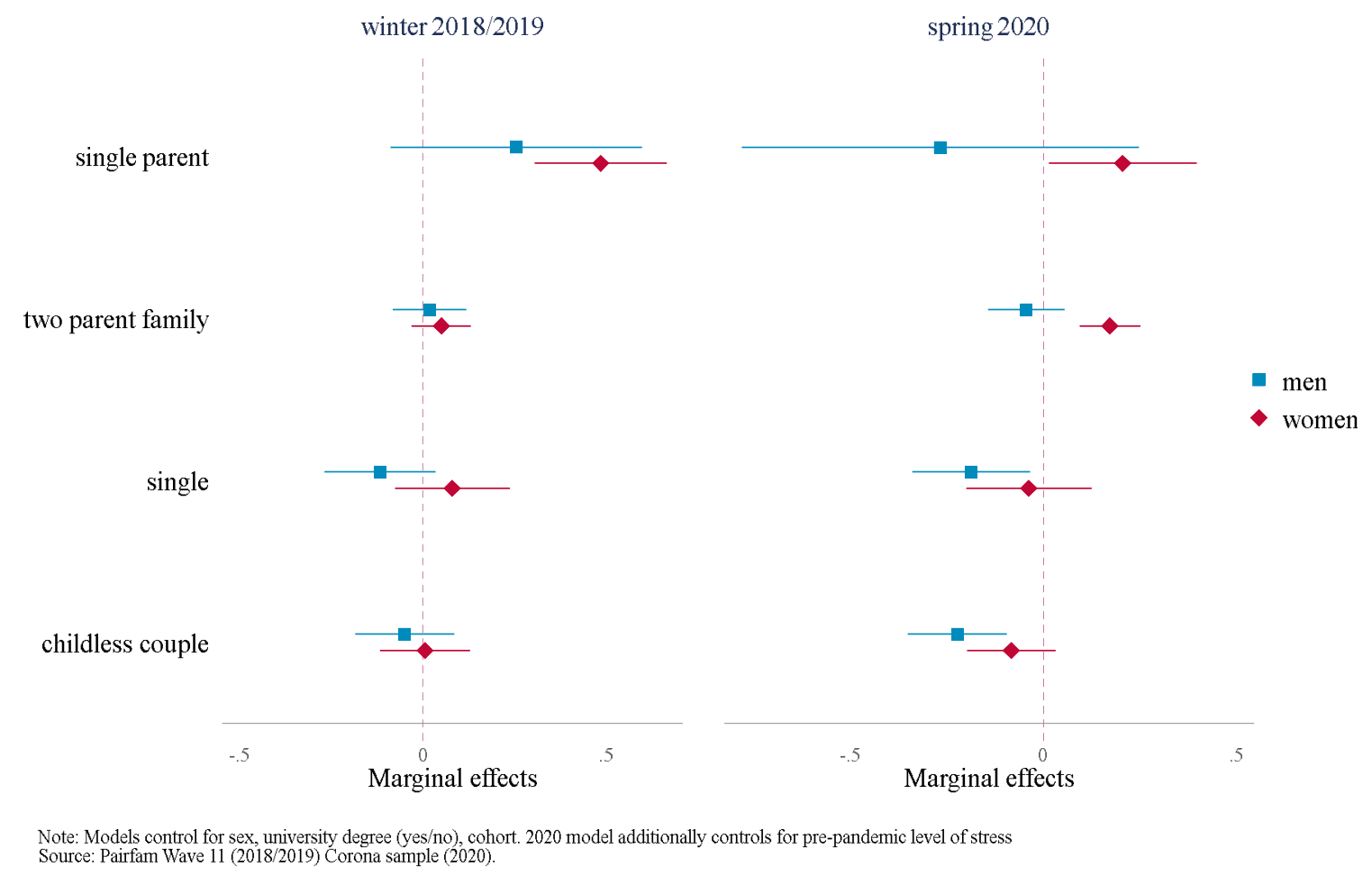

Figure 4 Gender differences in the association between family type and stress before and during the pandemic in Germany

Regarding a lack of energy, the interaction analyses on the pre-pandemic sample did not uncover any systematic gender differences by family type. In spring 2020, a clear gender gap emerged, with the mothers in both single-parent families and two-parent families being more likely to report a lack of energy than the fathers in both family types. Single mothers experienced greater increases in a lack of energy than partnered mothers, single women, and partnered childless women (and men). Regarding a lack of energy, the emerging gender gap between single mothers and all other women (and men) was significant, and was equivalent to half a standard deviation above the mean of the sample. The main effect of gender was still significant in this interaction model, which suggests that the increase in a lack of energy observed among mothers (vs. among fathers) could not explain all of the gender gap in a lack of energy. 


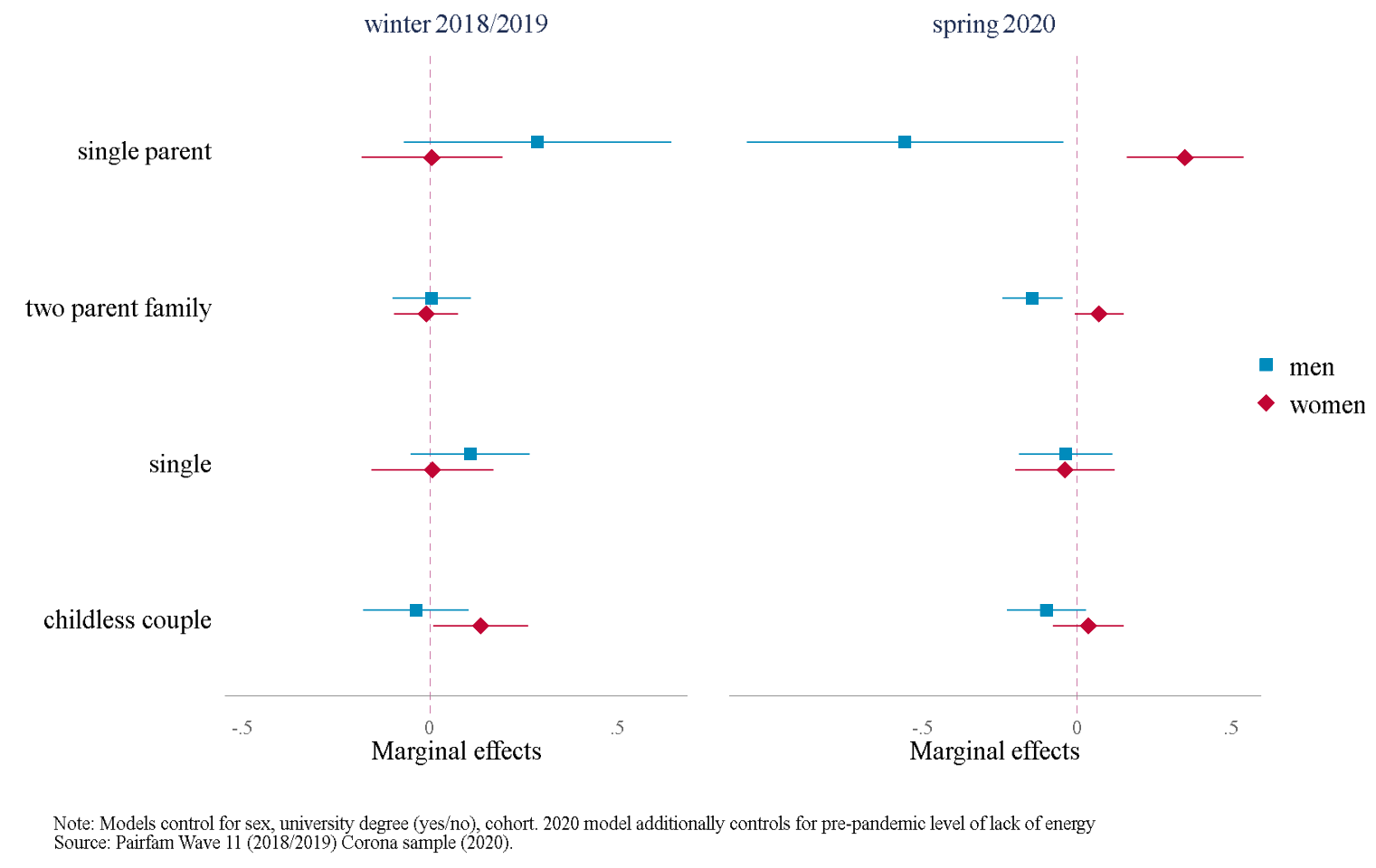

Figure 5 Gender differences in the association between family type and lack of energy before and during the pandemic in Germany

As was the case for the other dimensions of mental health, the pre-pandemic levels of loneliness did not differ between men and women of the same family type. In addition, as in the case of stress and energy levels, we observe an emerging gender gap in loneliness among partnered mothers and their male counterparts. When we look at this dimension of mental health, we see that this gap emerged because the women in two-parent families reported levels of loneliness that were closer to those of unpartnered mothers with and without children. 


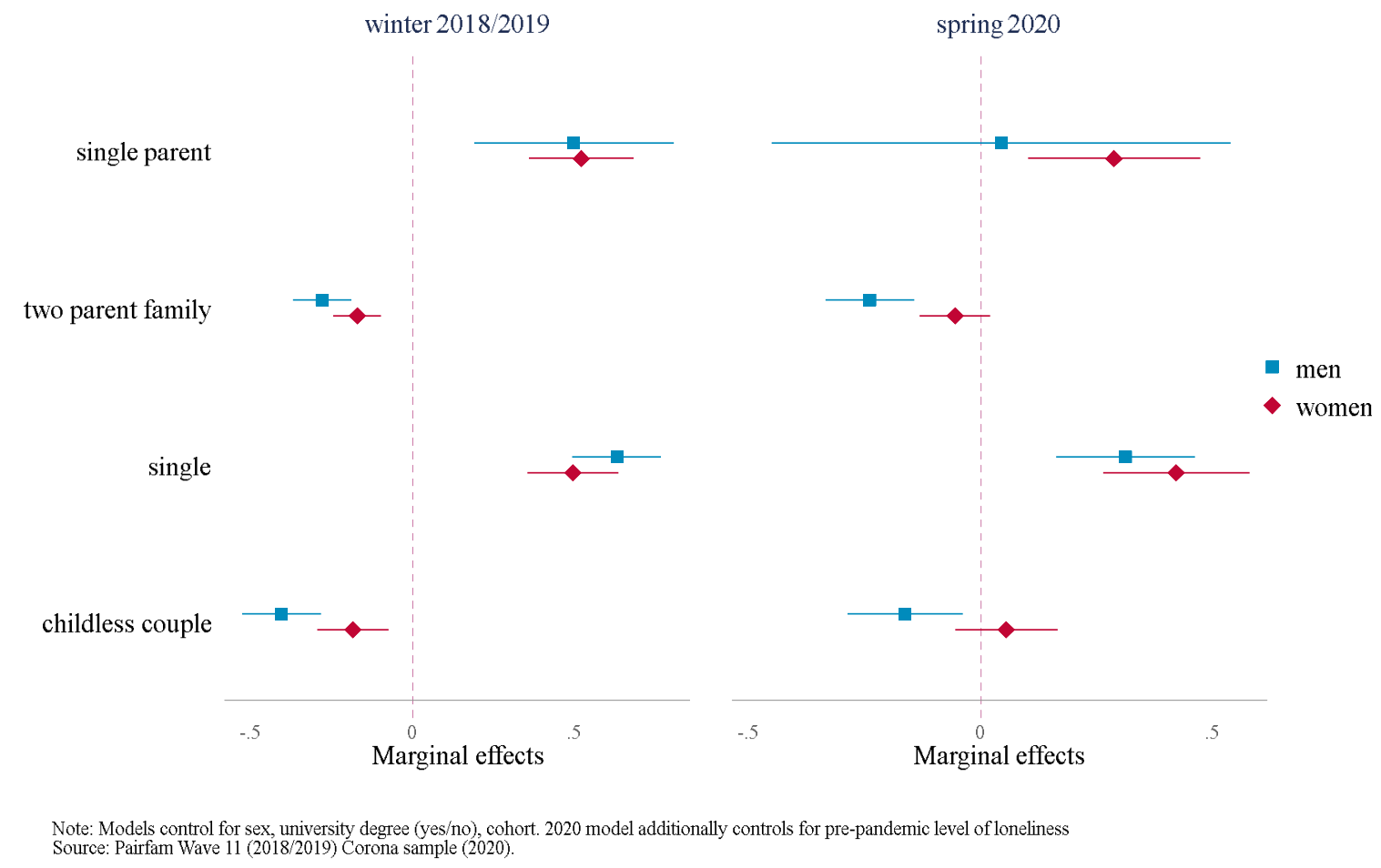

Figure 6 Gender differences in the association between family type and loneliness before and during the pandemic in Germany

Taken together, the findings on the pre-pandemic measures of mental well-being suggest that the expected gender differences formulated in Hypothesis 3 could not be validated by our data. One year prior to the pandemic, men and women were reporting similar levels of stress and lack of energy that were driven by parenthood, rather than by their partnership status; as well as similar levels of loneliness, which were, in turn, driven by their partnership status, rather than by their parenthood status. In spring 2020, mothers - and especially mothers living with a partner and children - reported having higher levels of stress, lack of energy, and loneliness than fathers.

As the emerging gender gap in mental health between mothers and fathers in two-parent families was striking, we ran a further set of explorative analyses to better understand where this gap may have come from. We report these analyses in detail in the supplementary material for this paper. 
The results indicate that unequal child care demands and gendered work-family conflicts may explain some of the mental health gap between mothers and fathers during the pandemic. For stress and loneliness, but not for a lack of energy, we find a clear mental health disadvantage among mothers when the youngest child was preschool age, but smaller (preschool) or non-existent (secondary) differences between the mothers and fathers of school-aged children (Figures S1 to S3 in the supplementary material). For stress, but not for energy and loneliness, we find clear evidence that the gender gap in stress among two-parent families is explained by the mothers of preschoolaged children who were working from home reporting significantly higher stress levels than their female counterparts who were not working from home (Figure S4 in the supplementary material). These findings suggest that the mental health of mothers was more negatively affected by workfamily conflicts during the spring lockdown in Germany.

\section{DISCUSSION}

This study set out to investigate whether the narrative that the growth in social inequalities during the COVID-19 pandemic that has been observed for a wide range of social and economic factors also applies to dimensions of mental health. For German men and women of the working-age population who belonged to the four most common family types, we studied three dimensions of mental health: levels of stress, exhaustion, and loneliness. We analyzed measures of self-reported mental health one year before the pandemic and during the first infection wave in spring 2020, when major non-pharmaceutical public health measures were in place that imposed unprecedented limits on social support and integration for most of the German population. Our analyses showed that mental health disparities by family status differed depending on the dimension of mental health investigated, thus underlining the empirical and substantive benefits of studying mental health outcomes from a multidimensional perspective. The pre-pandemic measures indicated that single 
parents (the vast majority of whom were single mothers) had significantly higher stress levels than all other family types, which is in line with a well-established literature showing that the mental health disadvantages observed among single mother are mainly attributable to the high and continuous stress levels they are exposed to (Avison et al. 2007; Crosier et al. 2007). We did not find significant group differences in stress levels between partnered parents and childless couples or singles. In addition, the pre-pandemic differences by family type in a lack of energy were not shown to be significant, whereas measures of aspects of mental health that capture loneliness indicated that unpartnered individuals had a clear mental health disadvantage compared to partnered individuals.

The measures of mental health during the pandemic suggest that mental health disparities between types of family were emerging in spring 2020 that were not previously observed. In particular, there was a convergence of relatively high stress levels among the family types with children, irrespective of the partnership status. However, while partnered parents had significantly higher stress levels compared to the sample mean, the findings for single parents were not significant. We were admittedly surprised that our analyses did not reveal larger differences in stress levels between single parents and the other family groups during the spring lockdown. It is possible that single parents were able to activate an already established informal support network when institutional support was not available. In addition, emergency child care - which was initially only available to so-called essential workers - was increasingly made available to single parents during the spring lockdown. Interestingly, similar findings were reported in a study based on Australian data, which showed that although single mothers were the most severely time-stressed group in the prepandemic period, they experienced the most time stress relief during the pandemic (Craig and Churchill 2021). The authors explained this result by speculating that single mothers, who were 
more likely than partnered mothers to be working full-time, may have been disproportionately relieved of work expectations when kindergardens and schools were closed.

In contrast, the mental health measure that captures exhaustion showed that single mothers had a significant disadvantage during the spring lockdown, while the results remained non-significant for all other family types. This suggests that the finding that the stress levels of single mothers declined in the early phase of the pandemic was not replicated when looking at their levels of exhaustion, which further strenghtens the argument that multiple health indicators need to be analyzed before drawing firm conclusions about the mental health status of different groups during a global health crisis, and the social inequalities between these groups. Similarly, a study that focused on the parenting-related exhaustion during the Italian COVID-19 lockdown found that mothers experienced greater exhaustion than fathers, particularly when they were single, had children with special needs, had a larger number of children, or had younger children (Marchetti et al. 2020). Earlier studies have shown that a lack of resilience can produce overwhelming exhaustion (Mikolajczak et al. 2018), which might explain why single parents in particular are prone to having higher levels of exhaustion. The gaps in loneliness narrowed slightly between the family types, but this was due to everyone feeling lonelier than they did before. Given the evidence that persistent feelings of loneliness increase the risk of developing serious mental health problems (Mushtaq et al. 2014; Nuyen et al. 2020), these findings point to a general population health concern that should be given greater attention by policy-makers seeking to mitigate the effects on mental health of the current and future pandemics.

The second set of analyses focused on gender differences in stress, a lack of energy, and loneliness by family status. Our analyses of the pre-pandemic measures of mental health showed that men and women reported similar levels of stress and lack of energy, which were driven by parenthood 
rather than by partnership status; as well as similar levels of loneliness, which were, in turn, driven by partnership status rather than by parenthood status. This narrative did not hold during the pandemic. Mothers reported significantly higher levels of stress, lack of energy, and loneliness than fathers, and this gap was particularly striking for mothers living with (!) the father of their children. Thus, partnered mothers in Germany emerge as a new vulnerable group during the current global health crisis. Our supplementary analyses suggest that mothers suffered more than fathers from having to balance child care, work, and, most likely, additional domestic work during the spring lockdown. The widening gender gap in mental health found among parents is in line with US-based research (Adams-Prassl et al. 2020), and with studies that focused on German families (Huebener et al. 2021; Zoch et al. 2020).

Due to the different response behaviors to the additional coronavirus survey, highly educated individuals were overrepresented in our sample. High SES individuals undeniably tended to have more resources, first to adhere to the non-pharmaceutical public health measures implemented in spring 2020, and second to mitigate the negative consequences associated with it. Thus, it is possible that the negative mental health disparities in the general population are larger than those reported in our results. However, the key findings presented here - namely, that there is a growing mental health gap between parents and non-parents that seems to be largely driven by an emerging gender gap in the mental health of mothers and fathers - may be attributed to women of higher socioeconomic status in particular. Compared to their lower educated female counterparts, these women are socially advantaged because they have been less exposed to actual infection risk, as they are less likely to have a so-called system-relevant job with a high exposure risk, and are more likely to be able to work from home. They are also advantaged in terms of their levels of economic protection, as they are less likely to be furloughed or to have their hours reduced. Moreover, they also tend to be advantaged in the sense that they are more likely to hold and to be partnered with a 
man who holds gender-egalitarian attitudes that call for a more equal division of care responsibilities. However, these advantages may be accompanied by a higher likelihood of experiencing dramatically increased work-family conflicts during the pandemic. Employers' efforts to support their staff by helping them reconcile child care and paid work was often limited to facilitating working from home and having flexible schedules - both of which tend to have more adverse effects on women (mothers) than men (fathers) (Lott 2020). Indeed, our supplementary analyses showed that mothers of younger children, and particularly those working from home, reported much higher levels of stress than their male counterparts. Hence, the gender gap in mental health may have especially affected highly educated mothers of small children, who were penalized the most due to their high levels of dependence on extra-household child care to reconcile their demanding paid work and the increasingly large demands on their time and energy to care for small children in the pandemic.

Since spring 2020, Germany has experienced two more and even larger waves of rapidly increasing infection rates. The country is still battling the pandemic with non-pharmaceutical public health measures, such as imposing contact restrictions and night curfews, and closing school and child care centers. One year later, these measures have been complemented by increasing vaccination rates among the German population, and increasing access to different types of diagnostic tests. Despite the general optimism that these pharmaceutical public health interventions in particular may be the game changers needed to overcome the pandemic, it is evident that many of the non-medical public health measures will have to stay in place until herd immunity can be reached. Parents and children are not prioritized in the efforts to reach herd immunity, and are therefore likely to be exposed to the pandemic longer than all other social groups. Thus, for more than one year and for an unforeseeable future, the stressors associated with contact restrictions that we argue are contributing to mental health disparities by family type and gender are accumulating. We have strong reasons to assume that the current mental health effects of the pandemic are larger than our results indicate. For the sample analyzed 
here, we suspect that the mental health disparities by family type and gender have since been expanding. Women, and particularly mothers, seem to carry the heaviest burden, and are thus at greatest risk of experiencing a mental health decline. This is worrisome in its own right, but also given that the poor mental health of mothers (and parents) has adverse consequences for their children. Thus, policy-makers should more seriously consider the disproportionate burdens that families carry due to the pandemic, both directly and indirectly. 


\section{Supplementary material}

The emerging gender gap in mental health within two-parent families

Increased child care demands may have affected mothers and fathers differently due to different gender role practices. In our sample, $40 \%$ of mothers, compared to $14 \%$ fathers, in two-parent families reported that they assumed the entire responsibility for child care during the spring lockdown. At the same time, almost twice as many men as women reported that they were sharing child care duties with their partner to some extent. We thus suspected that unequal child care demands could explain the mental health gap between mothers and fathers during the pandemic. We assessed the child care burden by first taking into account the age of the youngest child, distinguishing between preschool age (i.e., under age six), primary school age (i.e., six to $<10$ years), and secondary school age (10 to 18 years $)^{3}$. We also sought to capture the child care burden by the extent to which it conflicted with employment. For two-parent families, preschool child care centers and schools were closed in March - May/June 2020, and access to emergency care was given only to families with at least one partner working in crucial infrastructure. In our sample, less than $10 \%$ of respondents reported that their children used such emergency care during the spring lockdown. The biggest work-related change in our sample was the proportion of respondents

\footnotetext{
${ }^{3}$ In the coronavirus questionnaire, the age of child was not measured, and by deriving it from the age of the youngest child at wave 11, we would miss children born between 2018/19 and 2020. Thus, we derived the age group of the youngest child in three categories based on the respondents' answers to questions about the availability of preschool child care during the pandemic (respondents were invited to answer only if they had children in that age group), and their valid responses to a question on the grade level of their youngest child enrolled in school. We thus distinguished three age groups of a respondent's youngest child: preschool (i.e., below age six), primary school (i.e., age six to 10) and secondary school (i.e., age 11 -18). For the sake of the comparability of our results during the pandemic with the measures one year prior to the pandemic, we applied the same classification scheme for the youngest child in the prepandemic wave, although we had the exact age available (but not the grade level). As a consequence, we might have mis-classified some children in the pre-pandemic wave as being at a higher grade level than they were in reality. This is because in Germany, primary school entry takes place in August, and children who are born in September - December enter primary school at age seven (i.e., in the following year).
} 
who switched from working at their workplace to working from home during the spring lockdown. This change was observed among almost half of our sample, and the gender differences were larger than in any other work-related change that the parents in our sample experienced (50\% of fathers vs. $40 \%$ of mothers). We thus expected that work-family conflict levels may have been higher when performing paid work at home coincided with managing child care and/or schooling at home. We also assumed that women may have been more affected than men by these kinds of workfamily conflicts, with potentially adverse mental health consequences. For mothers and fathers in two-parent families, we predicted each of the mental health outcomes by the set of predictors from the main models, and added a two-way interaction between the sex of the respondent and the age group of the youngest child. The results are presented in Figures S1 to S3. The full regression models are presented in Table S1. For stress and loneliness, but not for a lack of energy, we found a clear gender gap in mental health to the disadvantage of mothers when the youngest child was preschool age, while the differences among mothers and fathers of school-aged children were smaller (preschool) or non-existent (secondary). However, as the main gender effect remained statistically significant, we cannot entirely explain the gender gap in the parents' mental health. 


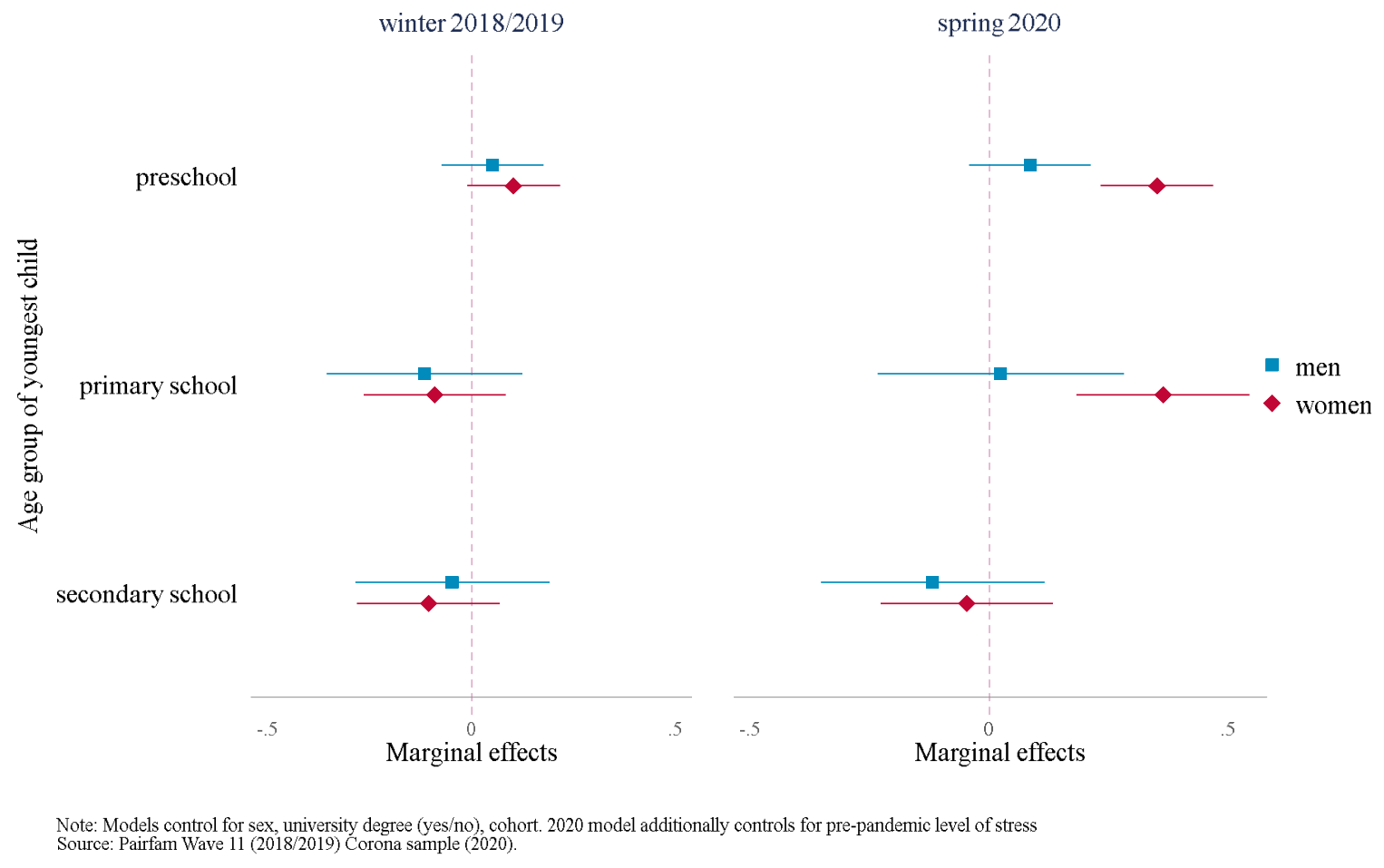

Figure S1. Gender differences in stress levels between mothers and fathers in two-parent families by age of the youngest child 


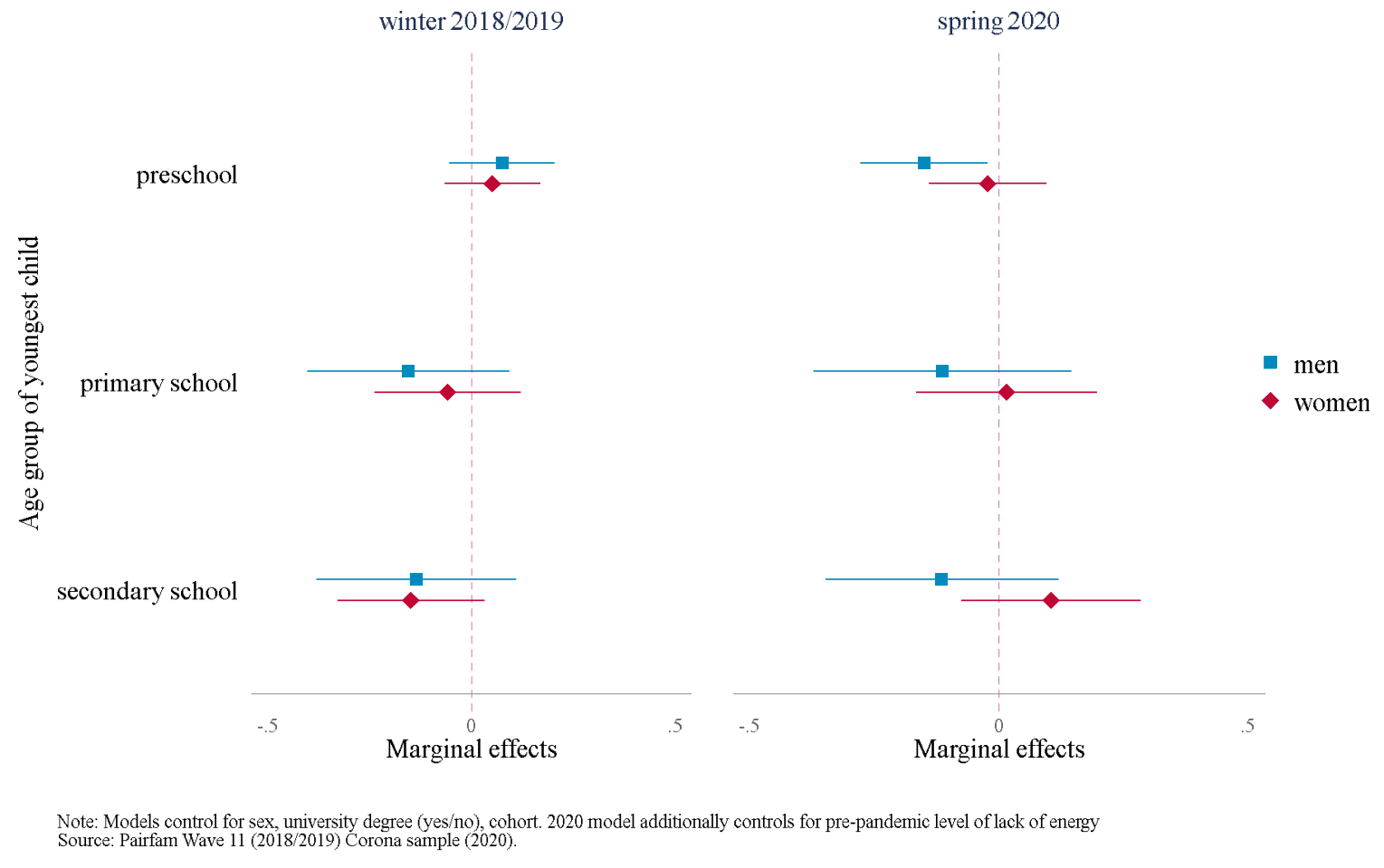

Figure S2. Gender differences in lack of energy levels between mothers and fathers in two-parent families by age of the youngest child 


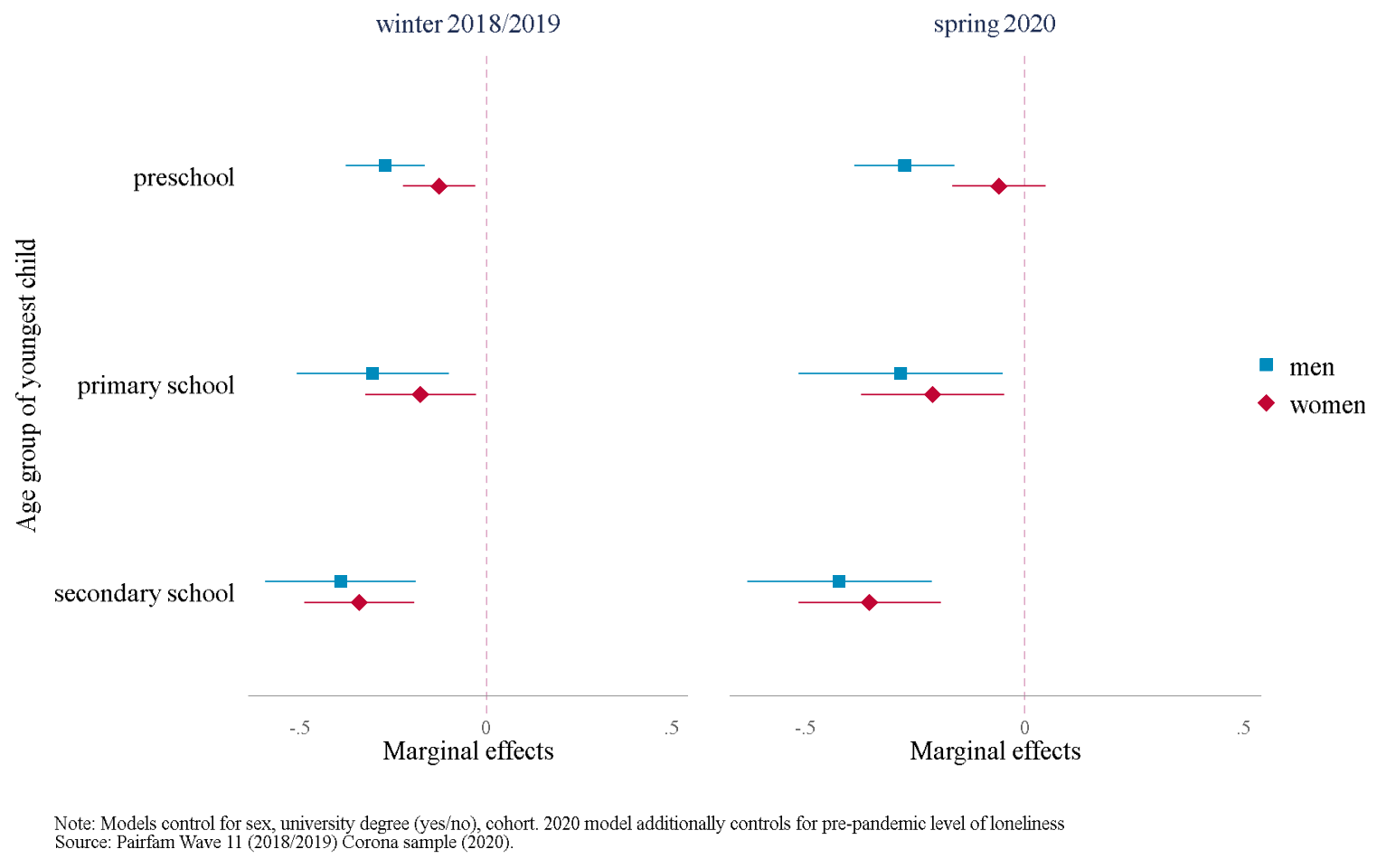

Figure S3. Gender differences in loneliness levels between mothers and fathers in two-parent families by age of the youngest child

In a second set of models, we added a three-way interaction between sex, age of the youngest child, and working from home. The results are presented in Figures S4-S6. The full regression models are presented in Table $\mathbf{S} 2$.

For stress, but not for energy and loneliness, we found clear evidence that the gender stress gap in two-parent families can be explained by mothers of preschool-aged children who were working from home reporting significantly higher stress levels than their female counterparts who were not working from home (Figure S4). The stress levels of mothers with a preschool-aged child who did not work from home in spring 2020 were equivalent to the predicted stress level of fathers who did work from home in the same period. These findings suggest that the mothers' mental health was more negatively affected by work-family conflicts during the spring lockdown in Germany. 


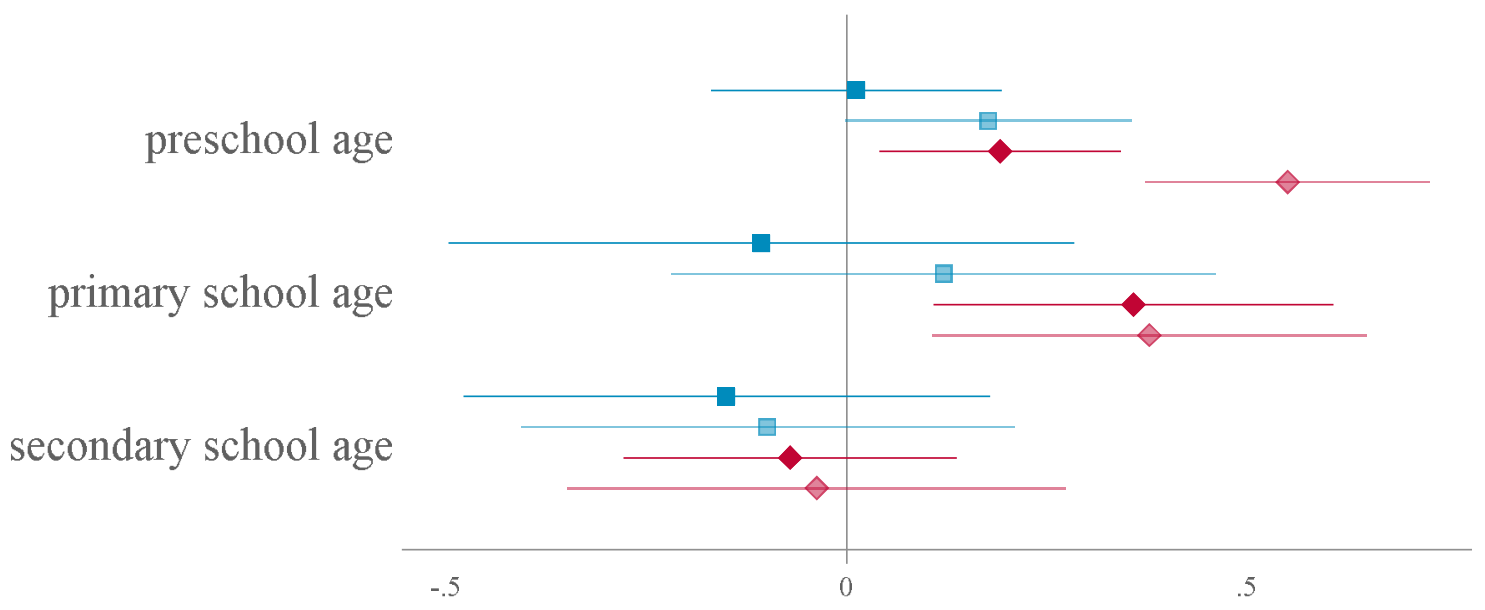

Marginal effects

- fathers no homeoffice $\square$ fathers homeoffice

$\checkmark$ mothers no homeoffice $\diamond$ mothers homeoffice

Note: Models control for sex, university degree (yes/no), cohort, pre-pandemic level of stress

Source: Pairfam Wave 11 (2018/2019) Corona sample (2020).

Figure S4. Gender differences in stress levels between mothers and fathers in two-parent families by age of the youngest child and working from home (vs. not) during the spring lockdown 


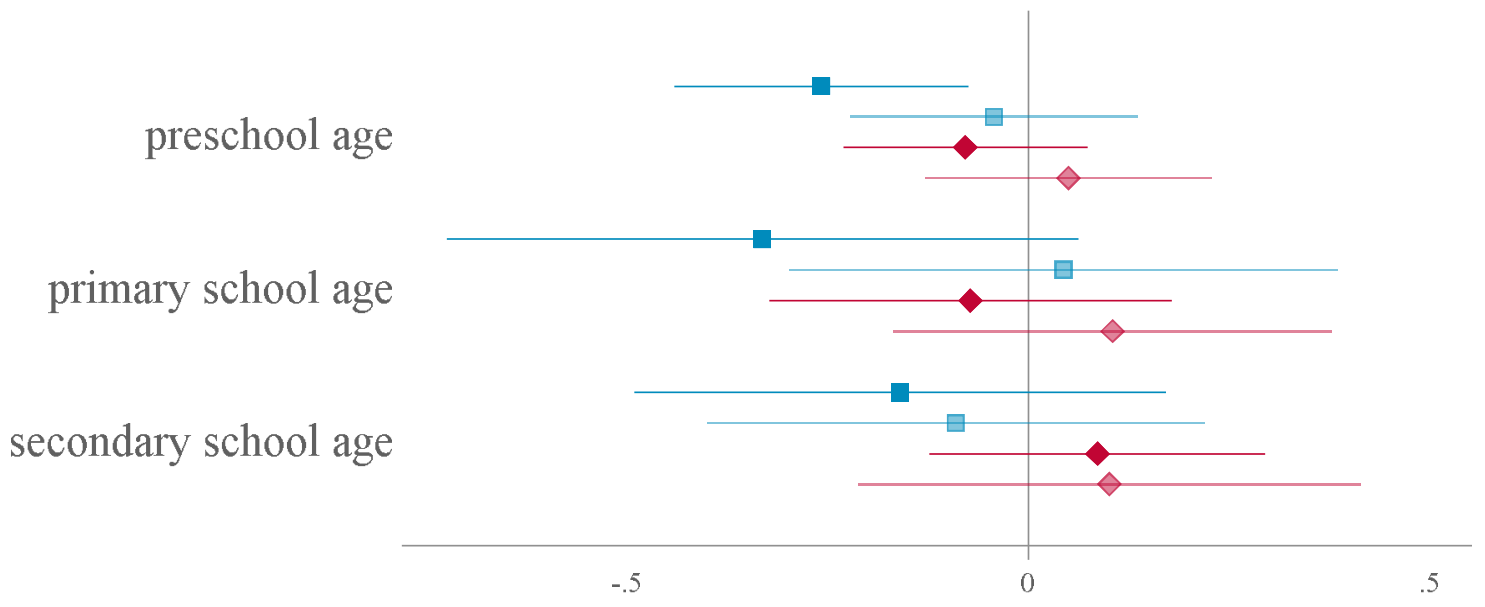

Marginal effects

- fathers no homeoffice $\square$ fathers homeoffice

mothers no homeoffice $\diamond$ mothers homeoffice

Note: Models control for sex, university degree (yes/no), cohort, pre-pandemic level of lack of energy

Source: Pairfam Wave 11 (2018/2019) Corona sample (2020).

Figure S5. Gender differences in lack of energy levels between mothers and fathers in two-parent families by age of the youngest child and working from home (vs. not) during the spring lockdown 


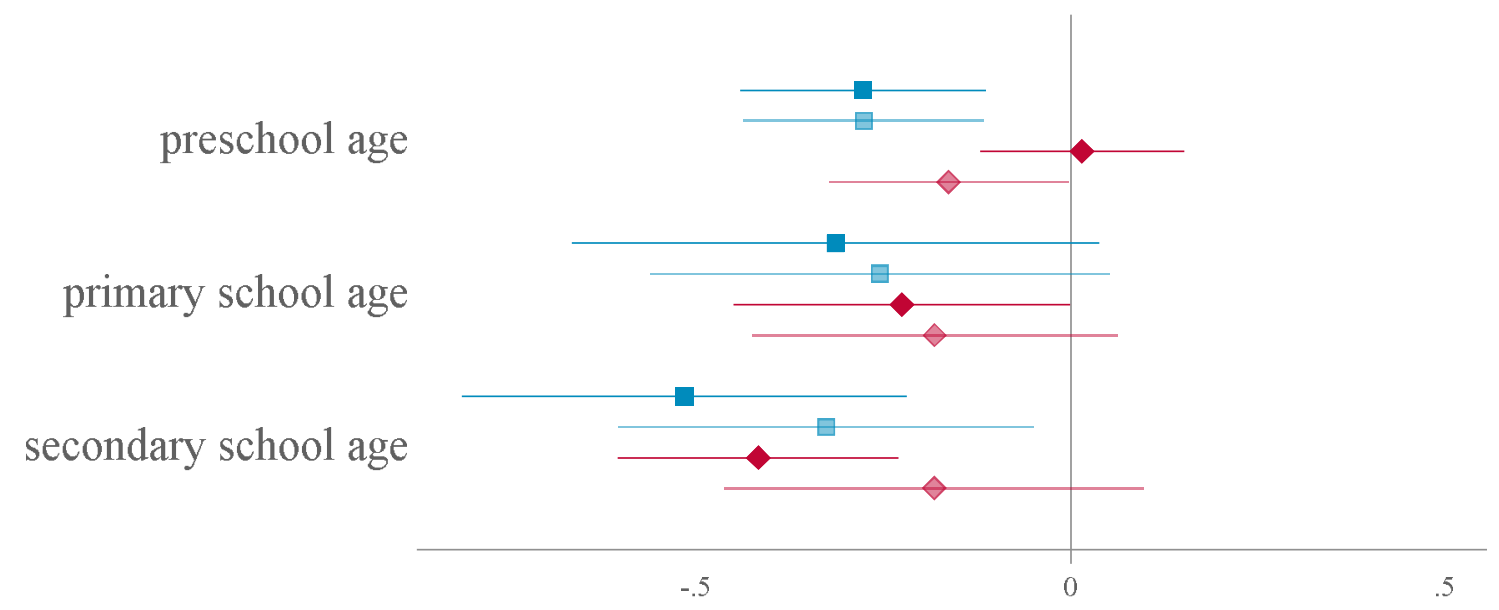

Marginal effects

- fathers no homeoffice $\square$ fathers homeoffice

$\checkmark$ mothers no homeoffice $\diamond$ mothers homeoffice

Note: Models control for sex, university degree (yes/no), cohort, pre-pandemic level of lack of loneliness

Source: Pairfam Wave 11 (2018/2019) Corona sample (2020).

Figure S6. Gender differences in loneliness levels between mothers and fathers in two-parent families by age of the youngest child and working from home (vs. not) during the spring lockdown 
Table S1. Results from linear regression models for $\mathrm{n}=847$ mothers and fathers in two-parent families predicting gender differences in levels of stress, lack of energy, and loneliness before and during the COVID-19 pandemic by age group of the youngest child ${ }^{4}$

\begin{tabular}{|c|c|c|c|c|c|c|}
\hline \multirow[b]{2}{*}{ Variable } & \multicolumn{2}{|l|}{ Stress } & \multicolumn{2}{|c|}{ Lack of Energy } & \multicolumn{2}{|c|}{ Loneliness } \\
\hline & $\begin{array}{l}\text { Before } \\
\text { pandemic }\end{array}$ & $\begin{array}{l}\text { Spring } \\
2020\end{array}$ & $\begin{array}{l}\text { Before } \\
\text { pandemic }\end{array}$ & Spring 2020 & $\begin{array}{l}\text { Before } \\
\text { pandemic }\end{array}$ & $\begin{array}{l}\text { Spring } \\
2020\end{array}$ \\
\hline Women (vs. men) & $\begin{array}{c}0.052 \\
(0.532)\end{array}$ & $\begin{array}{l}0.266^{* *} \\
(0.002)\end{array}$ & $\begin{array}{l}-0.023 \\
(0.785)\end{array}$ & $\begin{array}{c}0.128 \\
(0.136)\end{array}$ & $\begin{array}{c}0.146^{*} \\
(0.039)\end{array}$ & $\begin{array}{l}0.216^{* *} \\
(0.005)\end{array}$ \\
\hline Preschool (Reference) & & & & & & \\
\hline Primary school & $\begin{array}{l}-0.166 \\
(0.234)\end{array}$ & $\begin{array}{l}-0.062 \\
(0.678)\end{array}$ & $\begin{array}{l}-0.230 \\
(0.111)\end{array}$ & $\begin{array}{c}0.037 \\
(0.805)\end{array}$ & $\begin{array}{l}-0.033 \\
(0.781)\end{array}$ & $\begin{array}{l}-0.009 \\
(0.948)\end{array}$ \\
\hline Secondary school & $\begin{array}{l}-0.098 \\
(0.489)\end{array}$ & $\begin{array}{l}-0.203 \\
(0.146)\end{array}$ & $\begin{array}{l}-0.210 \\
(0.150)\end{array}$ & $\begin{array}{c}0.036 \\
(0.798)\end{array}$ & $\begin{array}{l}-0.120 \\
(0.321)\end{array}$ & $\begin{array}{l}-0.149 \\
(0.238)\end{array}$ \\
\hline $\begin{array}{l}\text { Woman*preschool } \\
\text { (Reference) }\end{array}$ & & & & & & \\
\hline $\begin{array}{l}\text { Woman*primary } \\
\text { school }\end{array}$ & $\begin{array}{l}-0.027 \\
(0.875)\end{array}$ & $\begin{array}{c}0.074 \\
(0.681)\end{array}$ & $\begin{array}{c}0.120 \\
(0.500)\end{array}$ & $\begin{array}{c}0.001 \\
(0.994)\end{array}$ & $\begin{array}{l}-0.016 \\
(0.911)\end{array}$ & $\begin{array}{l}-0.143 \\
(0.381)\end{array}$ \\
\hline $\begin{array}{l}\text { Woman*secondary } \\
\text { school }\end{array}$ & $\begin{array}{l}-0.110 \\
(0.491)\end{array}$ & $\begin{array}{l}-0.195 \\
(0.226)\end{array}$ & $\begin{array}{l}0.010 \\
(0.952)\end{array}$ & $\begin{array}{c}0.092 \\
(0.570)\end{array}$ & $\begin{array}{l}-0.096 \\
(0.485)\end{array}$ & $\begin{array}{l}-0.147 \\
(0.313)\end{array}$ \\
\hline $\begin{array}{l}\text { Pre-pandemic level of } \\
\text { mental health indicator } \\
\text { studied as outcome }\end{array}$ & & $\begin{array}{l}0.299 * * * \\
(0.000)\end{array}$ & & $\begin{array}{l}0.249 * * * \\
(0.000)\end{array}$ & & $\begin{array}{l}0.271 * * * \\
(0.000)\end{array}$ \\
\hline $\begin{array}{l}\text { University-educated } \\
\text { (vs. not) }\end{array}$ & $\begin{array}{l}0.095 \\
(0.141)\end{array}$ & $\begin{array}{l}0.025 \\
(0.703)\end{array}$ & $\begin{array}{l}-0.126 \\
(0.058)\end{array}$ & $\begin{array}{l}-0.024 \\
(0.721)\end{array}$ & $\begin{array}{l}-0.040 \\
(0.465)\end{array}$ & $\begin{array}{l}-0.094 \\
(0.115)\end{array}$ \\
\hline $\begin{array}{l}\text { Birth cohort } \\
1991-93 \\
1981-83 \text { (Reference) }\end{array}$ & $\begin{array}{l}-0.096 \\
(0.522)\end{array}$ & $\begin{array}{l}-0.258 \\
(0.096)\end{array}$ & $\begin{array}{l}-0.133 \\
(0.388)\end{array}$ & $\begin{array}{l}0.155 \\
(0.320)\end{array}$ & $\begin{array}{l}-0.037 \\
(0.769)\end{array}$ & $\begin{array}{l}0.338^{*} \\
(0.016)\end{array}$ \\
\hline $1971-73$ & $\begin{array}{l}-0.019 \\
(0.813)\end{array}$ & $\begin{array}{l}-0.096 \\
(0.269)\end{array}$ & $\begin{array}{l}-0.050 \\
(0.557)\end{array}$ & $\begin{array}{l}-0.250^{* *} \\
(0.004)\end{array}$ & $\begin{array}{c}0.105 \\
(0.131)\end{array}$ & $\begin{array}{c}0.011 \\
(0.887)\end{array}$ \\
\hline $\mathrm{N}$ & 916 & 847 & 916 & 847 & 916 & 847 \\
\hline R2 & 0.013 & 0.133 & 0.014 & 0.088 & 0.010 & 0.101 \\
\hline
\end{tabular}

p-values in parentheses

$* \mathrm{p}<0.05, * * \mathrm{p}<0.01, * * * \mathrm{p}<0.001$

Source: Pairfam 11 and coronavirus survey

\footnotetext{
${ }^{4}$ when the child is school age or younger.
} 
Table S2. Results from linear regression models for $\mathrm{n}=847$ mothers and fathers in two-parent families predicting gender differences in levels of stress, lack of energy, and loneliness before and during the COVID-19 pandemic by age group of the youngest child ${ }^{5}$ and working from home during the spring lockdown

\begin{tabular}{|c|c|c|c|}
\hline Variable & Stress & Lack of energy & Loneliness \\
\hline Women (vs. men) & $\begin{array}{c}0.180 \\
(0.129)\end{array}$ & $\begin{array}{c}0.179 \\
(0.133)\end{array}$ & $\begin{array}{l}0.292 * * \\
(0.006)\end{array}$ \\
\hline Worked from home (vs. not) & $\begin{array}{c}0.165 \\
(0.203)\end{array}$ & $\begin{array}{c}0.215 \\
(0.099)\end{array}$ & $\begin{array}{c}0.001 \\
(0.995)\end{array}$ \\
\hline \multicolumn{4}{|l|}{ Preschool (Reference) } \\
\hline Primary school & $\begin{array}{l}-0.119 \\
(0.589)\end{array}$ & $\begin{array}{l}-0.074 \\
(0.740)\end{array}$ & $\begin{array}{l}-0.037 \\
(0.853)\end{array}$ \\
\hline Secondary school & $\begin{array}{l}-0.162 \\
(0.402)\end{array}$ & $\begin{array}{c}0.098 \\
(0.616)\end{array}$ & $\begin{array}{l}-0.239 \\
(0.170)\end{array}$ \\
\hline Women*worked from home (vs. not) & $\begin{array}{c}0.194 \\
(0.254)\end{array}$ & $\begin{array}{l}-0.087 \\
(0.614)\end{array}$ & $\begin{array}{l}-0.179 \\
(0.245)\end{array}$ \\
\hline
\end{tabular}

Worked from home (vs. not)*preschool (Reference)

Worked from home (vs. not)* primary school

$\begin{array}{llc}0.063 & 0.160 & 0.058 \\ (0.829) & (0.585) & (0.825) \\ -0.114 & -0.145 & 0.189 \\ (0.653) & (0.569) & (0.408)\end{array}$

Women *preschool (Reference)

Women*primary school

0.285

0.080

$-0.204$

Women*secondary school

(0.276)

$(0.761)$

(0.388)

$-0.100$

0.067

$-0.194$

(0.652)

(0.766)

(0.334)

Women*worked from home*preschool (Reference)

Women*worked from home*primary school

$\begin{array}{lcc}-0.402 & -0.112 & 0.164 \\ (0.269) & (0.760) & (0.618) \\ -0.212 & 0.032 & 0.224 \\ (0.521) & (0.922) & (0.452)\end{array}$

Table continues on next page

Women*worked from home *secondary school

$(0.521)$

(0.922)

(0.452)

\footnotetext{
${ }^{5}$ when the child is school age or younger.
} 


\begin{tabular}{|c|c|c|c|}
\hline $\begin{array}{l}\text { Pre-pandemic level of mental health indicator } \\
\text { studied as outcome }\end{array}$ & $\begin{array}{l}0.291 * * * \\
(0.000)\end{array}$ & $\begin{array}{l}0.245^{* * *} * \\
(0.000)\end{array}$ & $\begin{array}{l}0.275^{* * * *} \\
(0.000)\end{array}$ \\
\hline University-educated (vs. not) & $\begin{array}{l}-0.038 \\
(0.593)\end{array}$ & $\begin{array}{l}-0.074 \\
(0.295)\end{array}$ & $\begin{array}{l}-0.095 \\
(0.134)\end{array}$ \\
\hline $\begin{array}{l}\text { Birth cohort } \\
\text { 1991-93 } \\
\text { 1981-83 (Reference) }\end{array}$ & $\begin{array}{l}-0.230 \\
(0.166)\end{array}$ & $\begin{array}{l}0.186 \\
(0.265)\end{array}$ & $\begin{array}{c}0.355^{*} \\
(0.018)\end{array}$ \\
\hline $1971-73$ & $\begin{array}{l}-0.080 \\
(0.361)\end{array}$ & $\begin{array}{l}-0.236 * * \\
(0.007)\end{array}$ & $\begin{array}{l}-0.008 \\
(0.915)\end{array}$ \\
\hline $\mathrm{N}$ & 837 & 837 & 837 \\
\hline R2 & 0.144 & 0.093 & 0.112 \\
\hline
\end{tabular}

$\mathrm{p}$-values in parentheses

$* \mathrm{p}<0.05, * * \mathrm{p}<0.01, * * * \mathrm{p}<0.001$

Source: Pairfam 11 and coronavirus survey 


\section{REFERENCES}

Abele-Brehm, A. and W. Brehm. 1986. "Zur Konzeptualisierung und Messung von Befindlichkeit: Die Entwicklung der "Befindlichkeitsskalen"(BFS) [On the concept and measurement of state of mind: The development of the state of mind scales]." Diagnostica 32(3).

Adams-Prassl, A., T. Boneva, M. Golin, and C. Rauh. 2020. "The impact of the coronavirus lockdown on mental health: Evidence from the US." HCEO Working Paper Series:1- 20.

Amato, P.R. 2000. "The consequences of divorce for adults and children." Journal of Marriage and Family 62(4):1269-1287.

Andrew, A., S. Cattan, M. Costa Dias, C. Farquharson, L. Kraftman, S. Krutikova, A. Phimister, and A. Sevilla. 2020. "How are mothers and fathers balancing work and family under lockdown?" in Institute for Fiscal studies. https://ifs.org.uk/publications/14860.

Avison, W.R., J. Ali, and D. Walters. 2007. "Family structure, stress, and psychological distress: A demonstration of the impact of differential exposure." Journal of Health and Social Behavior 48(3):301-317.

Blekesaune, M. 2008. "Partnership transitions and mental distress: Investigating temporal order." Journal of Marriage and Family 70(4):879-890.

Brown, S.L. 2000. "The effect of union type on psychological well-being: Depression among cohabitors versus marrieds." Journal of Health and Social Behavior 41(3):241-255.

Brüderl, J., S. Drobnič, K. Hank, F.J. Neyer, S. Walper, P. Alt, E. Borschel, C. Bozoyan, M. Garrett, S. Geissler, T.G. Avilés, N. Gröpler, K. Hajek, M. Herzig, B. Huyer-May, R. Lenke, R. Lorenz, K. Lutz, L. Minkus, T. Peter, T. Phan, R. Preetz, J. Reim, B. Sawatzki, C. Schmiedeberg, P. Schütze, N. Schumann, C. 
Thönnissen, K. Timmermann, and M. Wetzel. 2021. "The German Family Panel (pairfam)." GESIS Data Archive, Cologne ZA5678 Data file Version 12.0.0.

Bünning, M., L. Hipp, and S. Munnes. 2020. Erwerbsarbeit in Zeiten von Corona [Paid work during the Covid-19 pandemic]. Wissenschaftszentrum Berlin für Sozialforschung, Berlin.

Burgard, S.A. and J.A. Ailshire. 2013. "Gender and time for sleep among U.S. adults." American Sociological Review 78(1):51-69.

Carr, D. and K.W. Springer. 2010. "Advances in families and health research in the 21st century." Journal of Marriage and Family 72(3):743-761.

Craig, L. and B. Churchill. 2021. "Unpaid work and care during Covid-19: Subjective experiences of samesex couples and single mothers in Australia." Gender \& Society 0(0):08912432211001303.

Crosier, T., P. Butterworth, and B. Rodgers. 2007. "Mental health problems among single and partnered mothers." Social Psychiatry and Psychiatric Epidemiology 42(1):6-13.

Czymara, C.S., A. Langenkamp, and T. Cano. 2021. "Cause for concerns: Gender inequality in experiencing the COVID-19 lockdown in Germany." European Societies 23:68-81.

Evenson, R.J. and R.W. Simon. 2005. "Clarifying the relationship between parenthood and depression." Journal of Health and Social Behavior 46:341-358.

Fliege, H., M. Rose, P. Arck, S. Levenstein, and B.F. Klapp. 2001. "Validierung des “perceived stress questionnaire"(PSQ) an einer deutschen Stichprobe [Validation of the "Perceived Stress Questionnaire"(PSQ) in a German sample.]." Diagnostica 47(3):142-152. 
Gabor, C., K.D. Törő, J. Mokos, R. Sándor, H. Éva, K. Andrea, and F. Rita. 2020. "Examining perceptions of stress, wellbeing and fear among Hungarian adolescents and their parents under lockdown during the COVID-19 pandemic." PsyArXiv Preprint.

Gassman-Pines, A., E.O. Ananat, and J. Fitz-Henley. 2020. "COVID-19 and parent-child psychological well-being." Pediatrics 146(4).

Glass, J., R.W. Simon, and M.A. Andersson. 2016. "Parenthood and happiness: Effects of work-family reconciliation policies in 22 OECD countries." American Journal of Sociology 122(3):886-929.

Goldman, N. 2001. "Social inequalities in health disentangling the underlying mechanisms." Annals of the New York Academy of Sciences 954(1):118-139.

Goode, W.J. 1960. "A theory of role strain." American Sociological Review 25(4):483-496.

Hank, K. and A. Steinbach. 2020. "The virus changed everything, didn't it? Couples' division of housework and childcare before and during the Corona crisis." Journal of Family Research 33(1):99-114.

Hart, J. and W.-J. Han. 2020. "COVID-19 experiences and parental mental health." Journal of the Society for Social Work and Research 12(2).

Hiekel, N. 2014. The different meanings of cohabitation across Europe. How cohabiters view their unions and differ in their plans and behaviors. Amsterdam: Amsterdam University Press.

Huebener, M., S. Waights, C.K. Spiess, N.A. Siegel, and G.G. Wagner. 2021. "Parental well-being in times of Covid-19 in Germany." Review of Economics of the Household:1-32. 
Huinink, J., J. Brüderl, B. Nauck, S. Walper, L. Castiglioni, and M. Feldhaus. 2011. "Panel Analysis of Intimate Relationships and Family Dynamics (Pairfam): Conceptual framework and design." Journal of Family Research 23(1):77-101.

Janssen, L.H.C., M.-L.J. Kullberg, B. Verkuil, N. van Zwieten, M.C.M. Wever, L.A.E.M. van Houtum, W.G.M. Wentholt, and B.M. Elzinga. 2020. "Does the COVID-19 pandemic impact parents' and adolescents' well-being? An EMA-study on daily affect and parenting." PLOS ONE 15(10):1 - 21.

Johnson, D.R. and J. Wu. 2002. "An empirical test of crisis, social selection, and role explanations of the relationship between marital disruption and psychological distress: A pooled time-series analysis of fourwave panel data." Journal of Marriage and Family 64(1):211-224.

Kreyenfeld, M. and S. Zinn. 2020. "Coronavirus \& care: How the coronavirus crisis affected fathers' involvement in Germany." SOEPpapers on Multidisciplinary Panel Data Research No 1096.

Kühn, M. 2018. "Changes in lone mothers' health: A longitudinal analysis." Pp. 323-338 in Lone Parenthood in the Life Course, edited by L. Bernardi and D. Mortelmans. Cham: Springer International Publishing.

Lott, Y. 2020. "Does flexibility help employees switch off from work? Flexible working-time arrangements and cognitive work-to-home spillover for women and men in Germany." Social Indicators Research 151(2):471-494.

Marchetti, D., L. Fontanesi, C. Mazza, S. Di Giandomenico, P. Roma, and M.C. Verrocchio. 2020. "Parenting-related exhaustion during the Italian COVID-19 lockdown." Journal of Pediatric Psychology 45(10):1114-1123. 
Marcussen, K. 2005. "Explaining differences in mental health between married and cohabiting individuals." Social Psychology Quarterly 68(3):239-257.

Meadows, S.O., S.S. McLanahan, and J. Brooks-Gunn. 2008. "Stability and change in family structure and maternal health trajectories." American Sociological Review 73(2):314-334.

Meier, A., K. Musick, S. Flood, and R. Dunifon. 2016. "Mothering experiences: How single parenthood and employment structure the emotional valence of parenting." Demography 53(3):649-674.

Metsä-Simola, N. and P. Martikainen. 2013. "Divorce and changes in the prevalence of psychotropic medication use: a register-based longitudinal study among middle-aged Finns." Social Science \& Medicine 94:71-80.

Metsä-Simola, N. and P. Martikainen. 2014. "The effects of marriage and separation on the psychotropic medication use of non-married cohabiters: A register-based longitudinal study among adult Finns." Social Science \& Medicine 121:10-20.

Mikolajczak, M., M.E. Brianda, H. Avalosse, and I. Roskam. 2018. "Consequences of parental burnout: Its specific effect on child neglect and violence." Child Abuse \& Neglect 80:134-145.

Möhring, K., E. Naumann, M. Reifenscheid, A.G. Blom, A. Wenz, T. Rettig, R. Lehrer, U. Krieger, S. Juhl, S. Friedel, M. Fikel, and C. Cornesse. 2020. "Die Mannheimer Corona-Studie: Schwerpunktbericht zu Erwerbstätigkeit und Kinderbetreuung [The Mannheim Corona Study: Report on paid employment and childcare]." Mannheim: University of Mannheim.

Moon, J.R., M.M. Glymour, A.M. Vable, S.Y. Liu, and S.V. Subramanian. 2013. "Short- and long-term associations between widowhood and mortality in the United States: longitudinal analyses." Journal of Public Health 36(3):382-389. 
Mushtaq, R., S. Shoib, T. Shah, and S. Mushtaq. 2014. "Relationship between loneliness, psychiatric disorders and physical health ? A review on the psychological aspects of loneliness." Journal of Clinical and Diagnostic Research 8(9):WE01-WE04.

Musick, K., A. Meier, and S. Flood. 2016. "How parents fare: Mothers' and fathers' subjective well-being in time with children." American Sociological Review 81(5):1069-1095.

Negraia, D.V. and J.M. Augustine. 2020. "Unpacking the parenting well-being gap: The role of dynamic features of daily life across broader social contexts." Social Psychology Quarterly 83(3):207-228.

Negraia, D.V., J.M. Augustine, and K.C. Prickett. 2018. "Gender disparities in parenting time across activities, child ages, and educational groups." Journal of Family Issues 39(11):3006-3028.

Nelson, S.K., K. Kushlev, and S. Lyubomirsky. 2014. "The pains and pleasures of parenting: when, why, and how is parenthood associated with more or less well-being?" Psycholgical Bulletin 140(3):846-895.

Nomaguchi, K. and M.A. Milkie. 2020. "Parenthood and well-being: A decade in review." Journal of Marriage and Family 82(1):198-223.

Nomaguchi, K.M., M.A. Milkie, and S.M. Bianchi. 2005. "Time strains and psychological well-being: Do dual-earner mothers and fathers differ?" Journal of Family Issues 26(6):756-792.

Nuyen, J., M. Tuithof, R. de Graaf, S. van Dorsselaer, M. Kleinjan, and M.T. Have. 2020. "The bidirectional relationship between loneliness and common mental disorders in adults: findings from a longitudinal population-based cohort study." Social Psychiatry and Psychiatric Epidemiology 55(10):1297-1310.

Pilarz, A.R. and H.D. Hill. 2017. "Child-care instability and behavior problems: Does parenting stress mediate the relationship?" Journal of Marriage and Family 79(5):1353-1368. 
Ruppanner, L., F. Perales, and J. Baxter. 2019. "Harried and unhealthy? Parenthood, time pressure, and mental health." Journal of Marriage and Family 81(2):308-326.

Russell, D., L.A. Peplau, and C.E. Cutrona. 1980. "The revised UCLA Loneliness Scale: concurrent and discriminant validity evidence." Journal of Personality and Social Psychology 39(3):472.

Schmidt, A., A. Brose, A.C. Kramer, F. Schmiedek, M. Witthöft, and A.B. Neubauer. 2021. "Dynamic relations among COVID-19-related media exposure and worries during the COVID-19 pandemic." Psychology and Health: online ahead of print.

Simon, R.W. 2002. "Revisiting the relationships among gender, marital status, and mental health." American Journal of Sociology 107(4):1065-1096.

Simon, R.W. and J. Caputo. 2019. "The costs and benefits of parenthood for mental and physical health in the United States: The importance of parenting stage." Society and Mental Health 9(3):296-315.

Stavrova, O. and D. Fetchenhauer. 2015. "Married and cohabiting parents' well-being: The effects of a cultural normative context across countries." Journal of Social and Personal Relationships 32(5):601-632.

Strohschein, L., P. McDonough, G. Monette, and Q. Shao. 2005. "Marital transitions and mental health: are there gender differences in the short-term effects of marital status change?" Social Science \& Medicine 61(11):2293-2303.

Umberson, D., T. Pudrovska, and C. Reczek. 2010. "Parenthood, childlessness, and well-being: A life course perspective." Journal of Marriage and Family 72(3):612-629.

Waite, L., Y. Luo, and A. Lewin. 2009. "Marital happiness and marital stability: Consequences for psychological well-being." Social Science Research 38:201-212. 
Westrupp, E., C. Bennett, T.S. Berkowitz, G. Youssef, J. Toumbourou, R. Tucker, F. Andrews, S. Evans, S. Teague, and G. Karantzas. 2020. "Child, parent, and family mental health and functioning in Australia during COVID-19: Comparison to pre-pandemic data." PsyArXiv Preprint.

Zoch, G., A.-C. Bächmann, and B. Vicari. 2020. "Care-arrangements and parental well-being during the COVID-19 Pandemic in Germany." in IAB-Discussion Paper. 